\title{
Análisis arqueológico del pabellón occidental del palacio Al-Badi' de Marrakech
}

\author{
Archaeological analysis of the western pavilion of the palace of Al-Badi' \\ in Marrakech
}

\author{
Antonio Almagro \\ LAAC, Escuela de Estudios Árabes, CSIC. Granada \\ e-mail: aalmagro@eea.csic.es
}

\begin{abstract}
RESUMEN
Las ruinas del palacio al-Badi' son seguramente uno de los testimonios más sugerentes de lo que fue un edificio deslumbrador en su tiempo, llevado a un estado de obligada austeridad por efecto de su expolio sistemático. Sus dimensiones colosales hacen que sus restos aún estén revestidos de un carácter monumental que recuerda el de ciertas construcciones de la antigua Roma que nos evocan su pasada exhuberancia ornamental a través de meros detalles y sutiles huellas. Un detenido análisis de éstas, junto con un estudio comparativo con otros monumentos andalusíes de los que éste fue sin duda un emulador a una escala hasta entonces desconocida, nos permite plantear hipótesis sobre su forma y decoración originales que nos facilitan a su vez entender algunos de sus significados. El proceso metodológico seguido, que ha incluido un levantamiento detallado, el análisis de las huellas que permanecen en las estructuras existentes y el estudio comparativo con edificios anteriores y coetáneos desembocando en el recurso a las tecnologías infográficas, ha conducido a unos resultados que estimamos de interés para la mejor comprensión del carácter de esta magna obra que fue un portentoso epígono de la arquitectura andalusí.
\end{abstract}

Palabras clave: sa'adíes; al-Andalus; Marruecos; reconstrucción virtual.

\begin{abstract}
The ruins of the Palace of al-Badi' are surely one of the most suggestive testimonies of what was a dazzling building at the height of its time, which was later led to a state of forced austerity due to its systematic looting. Its colossal dimensions explain why its remains still possess a monumental character recalling that of certain constructions of ancient Rome, which evoke its past ornamental exuberance through mere details and subtle traces. A thorough analysis of these, along with a comparative study of other monuments of al-Andalus of which this was doubtless an emulator on a hitherto unknown scale, allows us to establish hypotheses on its original shape and decorations that, at the same time, helps to understand some of their meanings. The methodological process followed, which has included a detailed survey, the analysis of the remaining traces in the existing structures and a comparative study with earlier and contemporary buildings, culminates in the use of infographic technologies, and has produced results that we consider of interest to the better understanding of the nature of this prodigious epigone of the al-Andalus architecture.
\end{abstract}

Keywords: Saadian; al-Andalus; Morocco; virtual reconstruction.

Recibido: 17/07/2012. Aceptado: 15/04/2013.

Cómo citar este artículo / Citation

Antonio Almagro 2013: "Análisis arqueológico del pabellón occidental del palacio al-Badi' de Marrakech", Arqueología de la Arquitectura, 10: e008. doi: http://dx.doi.org/10.3989/arq.arqt.2013.002

\section{Copyright}

(c) 2013 CSIC. Este es un artículo de acceso abierto distribuido bajo los términos de la licencia Creative Commons Attribution-Non Commercial (by-nc) Spain 3.0. 


\section{NTRODUCCI ÓN}

El análisis arqueológico no busca sólo desentrañar la ubicación cronológica, y en su caso, la evolución en el tiempo, de un determinado elemento material, sino que aborda el conocimiento de su realidad física original y su interpretación funcional y simbólica. Dentro de esa evolución, los procesos destructivos sustraen valores y con ello información, a los testimonios del pasado, pero ello no puede ser causa de que cejemos en nuestra búsqueda de un conocimiento lo más completo posible de su realidad original. La lectura, lo mismo de presencias como de ausencias, desvelada muchas veces por sutiles huellas, permite llegar a reconstruir realidades hoy desaparecidas y procesos de creación y trasformación a través de los cuales podemos alcanzar a conocer numerosos episodios de su existencia y a través de ellos, de la historia de quienes los crearon o usaron.

El palacio al-Badi' (Figs. 1 y 2) fue un edificio de corta vida, nacido por voluntad de un soberano para satisfacer sus ansias de protagonismo y sus pretensiones políticas y que sucumbió apenas cien años después para satisfacer similares intereses materializados en otro lugar y sobre los que su predecesor arrojaba una sombra insoportable. Sometido a un expolio implacable que hizo desaparecer todo atisbo de su esplendor original, sólo quedaron sus muros desnudos y descarnados que

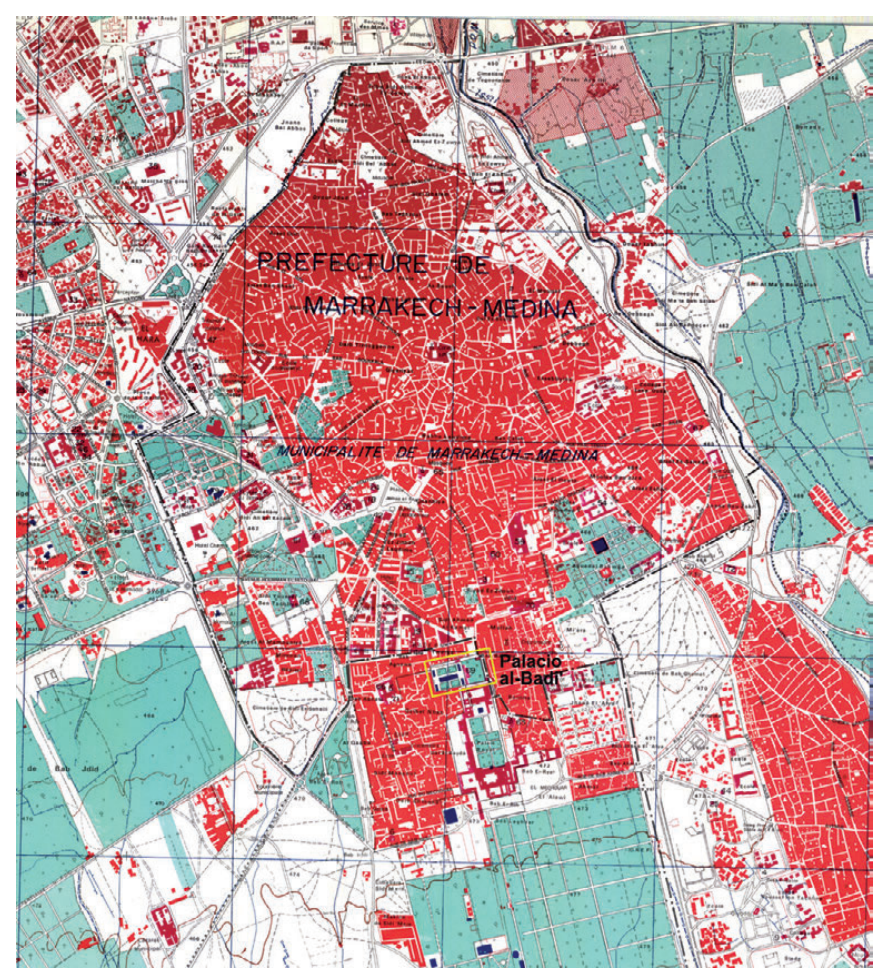

Figura 1. Plano de situación del palacio al-Badi' en la ciudad de Marrakech

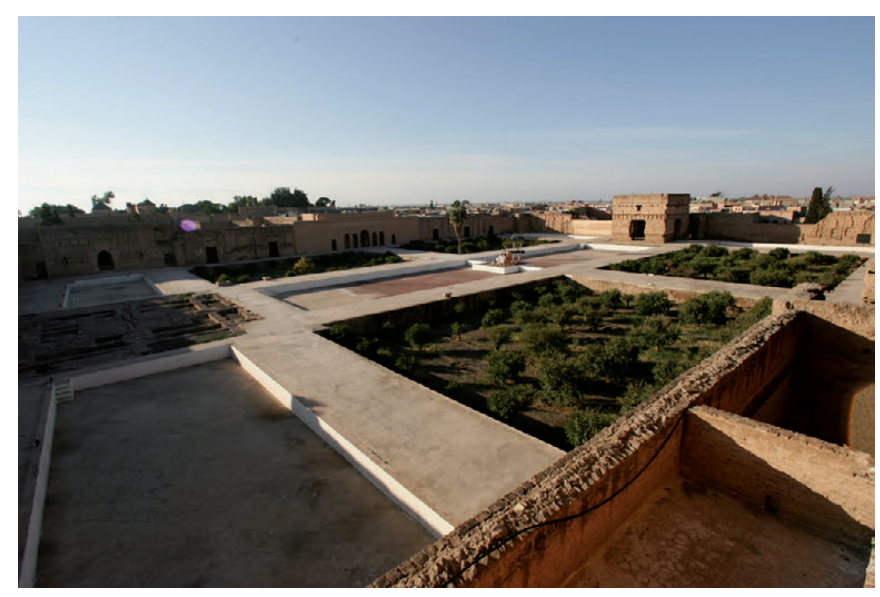

Figura 2. Vista actual del palacio al-Badi' de Marrakech

sin embargo, a través de sus cicatrices, nos hablan de los materiales que los adornaron y las estructuras con que se cubrieron, permitiéndonos de ese modo imaginar, si no en sus detalles, si en su impacto visual, el efecto que produciría la percepción de los espacios arquitectónicos que conformaron este singular palacio.

En este trabajo hemos abordado el análisis de una parte mínima del conjunto arquitectónico, el pabellón o qubba occidental (Fig. 3), que reúne a nuestro entender unas características que facilitan el estudio. Fue posiblemente un salón del trono del palacio, y por tanto un foco de atención singular dentro del conjunto áulico, no sólo por su forma y situación, sino seguramente también por la decoración que lo adornaba. Los muros maestros de su estructura están casi intactos en su altura y forma y pese al expolio y destrucción de sus revestimientos, las huellas dejadas sobre sus caras facilita la identificación de los elementos que los recubrían. Aunque privado de cubierta, numerosas huellas permitían plantear hipótesis sobre la forma en que se cerraba el espacio en su parte superior. Además, cuando iniciamos nuestros estudios, apenas había sido objeto de alguna intervención restauradora, por lo que sus restos eran aún perfectamente legibles. También su suelo había sido excavado y se encontraba limpio, presentando abundantes restos y huellas que hacían posible analizar numerosos detalles de un sofisticado sistema hidráulico ligado a la decoración y ambientación del salón interno. A todo esto se debe añadir la información documental de la que luego hablaremos, y que nos ha permitido plantear las hipótesis que presentamos.

En esta zona concreta del palacio no cabe hacer un análisis estratigráfico pues todo parece indicar que este pabellón sea obra de un solo momento y que las superposiciones de elementos que pueden observarse obedecen exclusivamente 


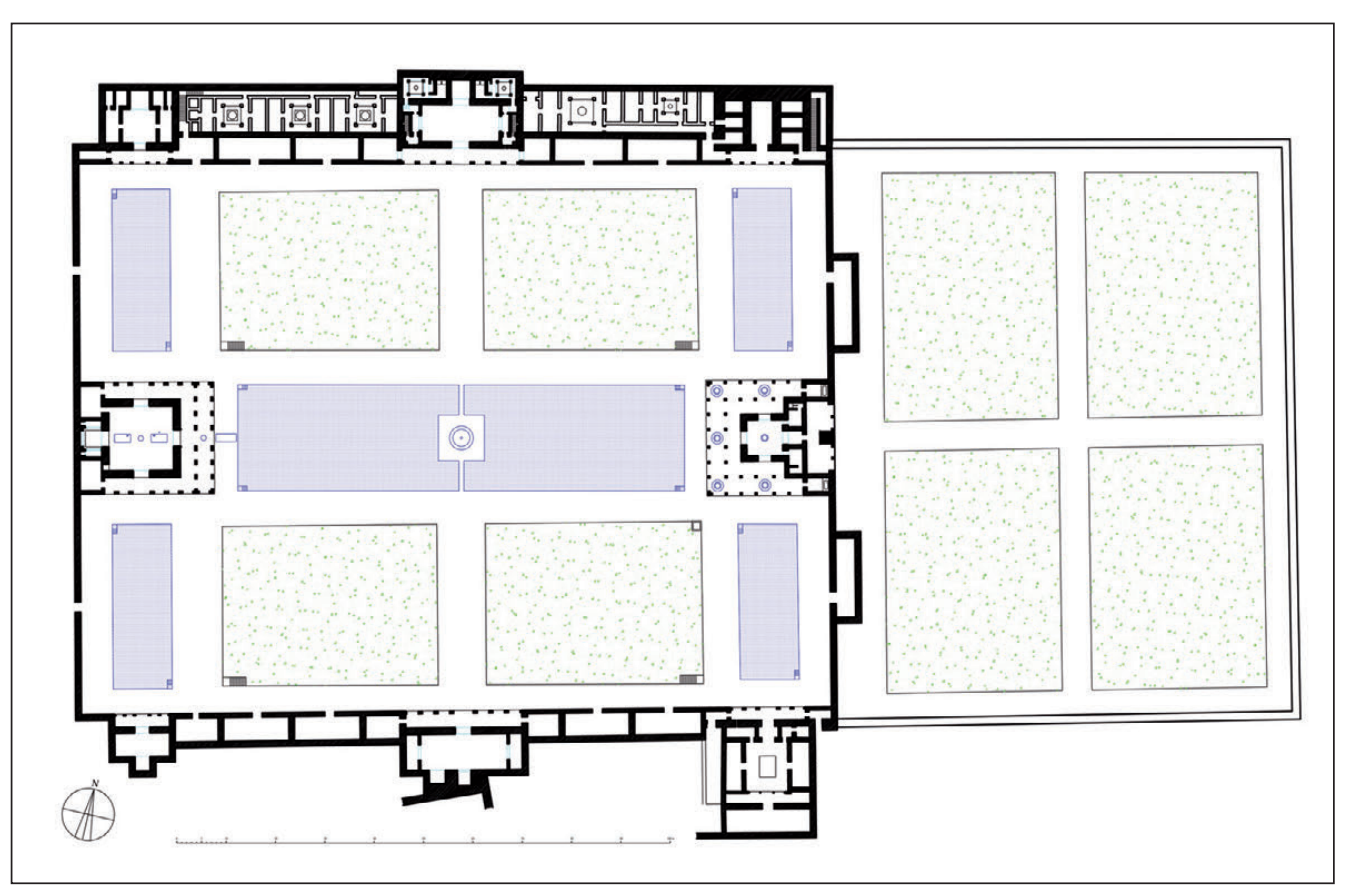

Figura 3. Planta del palacio al-Badi' al breve desfase temporal producido en un proceso constructivo normal realizado en un único momento cronológico. Hay indicios de que hubo algún uso marginal posterior al expolio ${ }^{1}$, pero casi todo lo que aportó debió ser eliminado en las restauraciones realizadas tras su excavación en la época del protectorado francés de Marruecos.

\section{METODOLOGÍ A}

El proceso seguido ha sido el habitual en nuestros trabajos $^{2}$. Lo iniciamos con la toma de datos de fotografías realizada con una cámara Canon EOS 1D de 8 Mpix. de resolución y objetivo de $14 \mathrm{~mm}$ (equivalente a $20 \mathrm{~mm}$ para formato 24 x $36 \mathrm{~mm}$ ) convenientemente calibrada para uso fotogramétrico. Se croquizó la planta y se midió con un metro-láser Leica Disto, incluyendo el levantamiento de las estructuras hidráulicas del suelo.

A continuación se realizaron los dibujos de estado actual (Fig. 4). Para ello se orientó un bloque de 14 fotografías que cubrían todos los paramentos, tanto exteriores como interiores, de la sala y que conformaban además 7 pares estereoscópicos, usando el programa Orthoware ${ }^{3}$. Para la orientación absoluta se utilizaron algunas de las medidas tomadas manualmente y la referencia de un plano horizontal, para lo que aprovechamos la huella de la parte superior del zócalo de alicatado. Con este sistema

\footnotetext{
1 Alguna foto antigua muestra tapiado el hueco del arco oriental del pabellón y con una puerta rectangular (Deverdun 1959: Pl. XLII).

2 Almagro et al. 2008.

3 Desarrollado por Metria Digital. http://www.orthoware.es/cas/index.asp.
}

evitamos tener que usar un taquímetro u otro instrumento semejante. La precisión lograda, con errores de alrededor de $3 \mathrm{~cm}$, la consideramos suficiente para los objetivos de este trabajo pues resultan prácticamente inapreciables a la escala en que se reproducen los planos. Por este procedimiento obtuvimos coordenadas tridimensionales de 66 puntos que fueron utilizados como puntos de control para la orientación de los pares estereoscópicos con el programa VSD ${ }^{4}$. Una operación semejante se realizó para las dos pequeñas habitaciones del lado occidental, para las que se trabajó con 12 fotografías y 50 puntos, enlazando ambas restituciones por medio de puntos comunes.

Por medio de la restitución realizada con el auxilio de la visión estereóscópica se obtuvieron los dibujos tridimensionales de las siete caras visibles del edificio que al integrarse en un solo dibujo nos permitió obtener un modelo 3D que refleja su estado en el momento en que se realizó la toma de datos (Fig. 5). Este procedimiento, que venimos utilizando en muchos de nuestros trabajos, permite realizar los levantamientos con un tiempo muy breve de permanencia en el sitio y con instrumentos de coste muy reducido y fácilmente transportables a cualquier lugar 5 .

\footnotetext{
4 Desarrollado por la Universidad AGH de Cracovia.

5 En la actualidad el desarrollo de los instrumentos y el software han permitido mejorar los resultados. Ahora usamos una cámara digital Canon EOS 1Ds de 21 Mpixels, de formato completo 24 x $35 \mathrm{~mm}$, con objetivos de 20 y 28 mm y el programa de restitución que empleamos es Poivilliers F, desarrollado por Yves Egels del IGN de Francia (Almagro 2011).
} 


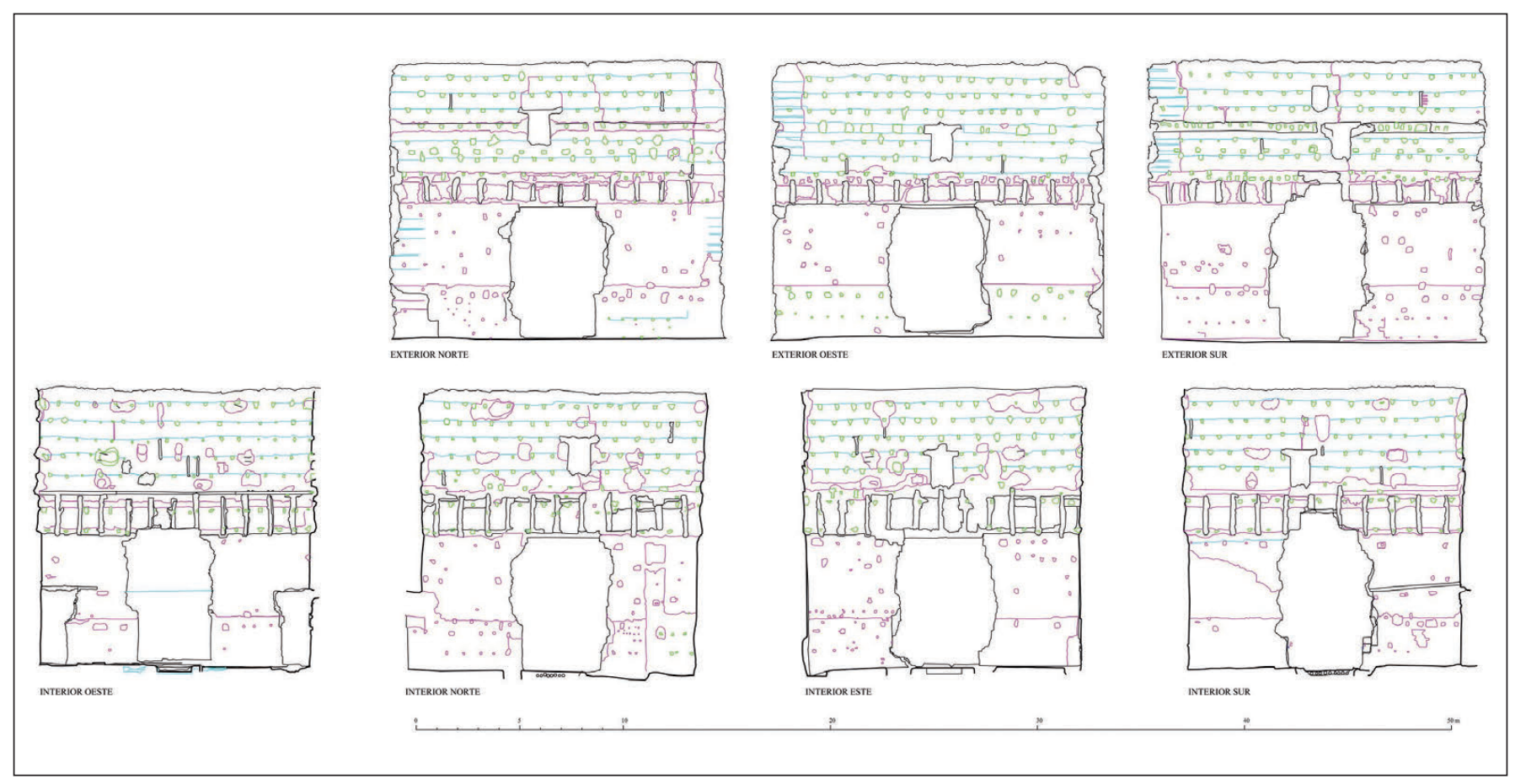

Figura 4. Alzados exteriores e interiores del pabellón occidental del palacio al-Badi'

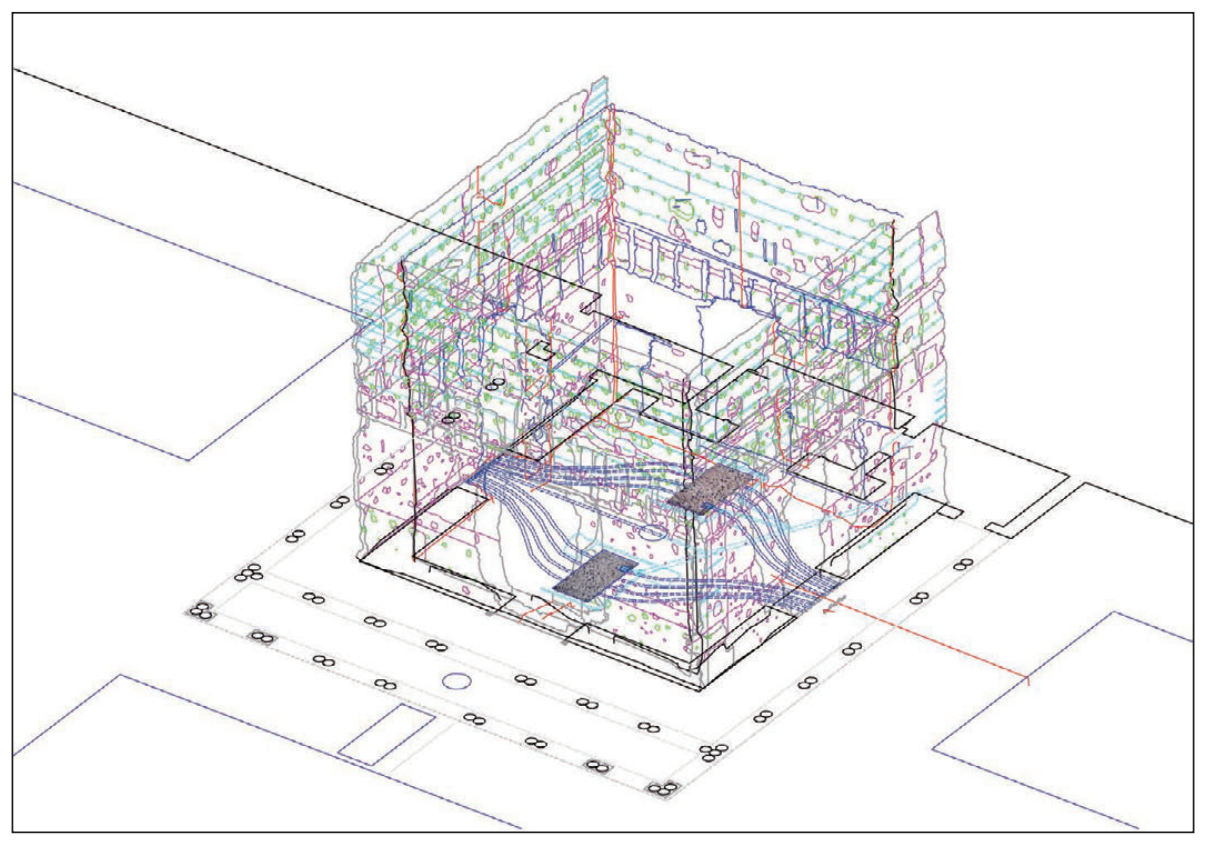

Figura 5. Modelo tridimensional del pabellón occidental

Sobre la base de la planimetría obtenida iniciamos el estudio de las propuestas de reconstrucción que basamos en las huellas que se conservan en el monumento y en el estudio comparativo con otros edificios semejantes, lo mismo contemporáneos como de períodos anteriores. En este caso, tal proceso se ha realizado tanto mediante la inspección ocular in situ, como por observación de los pares estereoscópicos que permiten generalmente ver con mayor comodidad y detalle muchas de estas huellas. Para el estudio comparativo se ha recurrido a realizar otros levantamientos parciales de algunos de los edificios que presentan semejanzas. El estudio de fuentes, tanto escritas como gráficas, ayudó a completar la información. Con estos datos se inició el proceso de propuesta que se realizó primeramente mediante dibujos en 2D de plantas, alzados y secciones. A partir de 
estos dibujos se fue montando el modelo 3D, primero volumétrico, al que se le fueron agregando las texturas y posteriormente la iluminación, hasta poder realizar las oportunas imágenes “renderizadas”.

\section{DESCRI PCIÓN GENERAL}

El palacio al-Badi' de Marrakech es seguramente uno de los conjuntos áulicos más imponentes del occidente islámico, no sólo por sus enormes dimensiones, totalmente fuera de lo habitual en edificios anteriores de su mismo carácter, sino también por lo original de su estructura y disposición. Todo ello justifica sobradamente el nombre que se le dio: al- Badi', el Incomparable. Sus restos ocupan una amplia área de lo que fue la qasba sa'adí de Marrakech y formaban parte del gran conjunto palatino allí levantado sobre el mismo emplazamiento que ocupó la anterior qasba almohade ${ }^{6}$.

Resulta imposible analizar esta magna obra sin hacer una referencia a la vida y acciones de su promotor, el sultán sa'adí Ahmad al-Mansur al-Dehbhi ${ }^{7}$, ya que esta obra sólo cobra pleno sentido dentro de la acción política y de la ambición que siempre marcaron las líneas de su gobierno. Bajo su mandato, que se extiende entre 1578 y 1603 Marruecos alcanzó uno de sus periodos de mayor pujanza y prosperidad de la Edad Moderna. Con esta suntuosa y monumental obra se propuso sin duda crear un marco arquitectónico que constituyera un respaldo a su política encaminada a sustentar su legitimidad y la construcción de una ideología imperial ${ }^{8}$.

Ahmad era el sexto hijo de Muhammad al-Sheij, primer monarca de la dinastía Sa’adí, que consiguió reunificar el territorio marroquí tras las luchas que desmembraron el sultanato meriní. Tras el asesinato de su padre y la subida al trono de su hermano 'Abd Allah al-Ghalib (1557-1574), él y su otro hermano 'Abd al-Malik se exiliaron para salvaguardar sus vidas, siendo acogidos en el imperio otomano, primero en Argel y después en Estambul, lo que le permitió tener un contacto directo con la cultura y el protocolo de la Sublime Puerta. A la muerte de 'Abd Allah, le sucedió su hijo Abu 'Abd Allah Muhammad II en contra del mayor derecho de 'Abd al-Malik, quien con ayuda turca consiguió finalmente derrotar a su sobrino que a su vez buscó apoyo al otro lado del estrecho de Gibraltar, comprometiendo la intervención portuguesa. En la batalla

\footnotetext{
Koehler 1940, Deverdun 1959: 384-412, Barrucand 1985: 114-122.

García Arenal 2009.

8 García Arenal 2009: 111-125.
}

de al-Qasr al-Kebir, también conocida como de los Tres Reyes (4 de agosto de 1578), fue totalmente derrotado el ejército portugués que bajo el mando del rey $\mathrm{D}$. Sebastián pretendía favorecer las aspiraciones del pretendiente Abu 'Abd Allah Muhammad II, que falleció en el transcurso de este encuentro, lo mismo que 'Abd al-Malik. La muerte de su hermano, ocurrida no a causa del combate sino de la enfermedad y las penalidades de la campaña, proporcionó a Ahmad al-Mansur la ocasión de apropiarse, no sólo del trono, sino de la gloria de la victoria que en verdad correspondía principalmente al monarca fallecido 9 .

Ahmad al-Mansur hubo de hacer frente a las presiones expansivas del imperio otomano, fuertemente asentado en los vecinos territorios de la actual Argelia, y a la realidad del final de al-Andalus y la presencia de potentes estados cristianos al otro lado del Estrecho. La desaparición del sultanato de Granada, acaecida apenas un siglo antes, y el hecho de que muchos de sus habitantes habían emigrado al norte de África, le permitía sentirse legítimo heredero de su legado, al contar entre sus súbditos a una parte considerable de los antiguos pobladores del reino nazarí. Al-Mansur estaba bien informado de cuanto sucedía en la Península Ibérica, e incluso de los planes constructivos de Felipe II de cuyas obras en El Escorial fue buen conocedor ${ }^{10}$. El desaparecido reino nazarí y los edificios y palacios levantados por sus soberanos constituyeron sin duda para él un referente al que acudir en busca de formas y modelos que permitieran sustentar sus pretensiones políticas y sin duda sirvieron de inspiración para la edificación de su palacio.

La construcción del palacio de al-Badi' se inició en diciembre de 1578, apenas unos meses después de la ascensión al trono de su promotor. El sustancioso botín logrado de los pertrechos de los vencidos en la batalla de al-Qasr al-Kebir, y los cuantiosos rescates que debieron pagar por su liberación muchos de los prisioneros portugueses capturados, proporcionaron fondos para el inicio de la construcción a los que se sumaron posteriormente las pingües rentas que generaba la producción azucarera del reino y los beneficios de la campaña de conquista del Sudán, que permitió el control del comercio del oro y los esclavos provenientes de esta región. Su construcción se

\footnotetext{
9 Es importante conocer todas estas vicisitudes para comprender el verdadero alcance y significado de la construcción del palacio, que fue un verdadero instrumento de legitimación frente a posibles cuestionamientos de su poder y sus derechos a detentarlo. A la muerte de al-Mansur se desataría de nuevo la guerra civil entre distintos pretendientes al trono.

${ }_{10}$ García Arenal 2009: 116.
} 
desarrolló hasta 1594, cuando fue inaugurado con una espléndida recepción, aunque en 1602, poco antes de la muerte de al-Mansur aún seguían haciéndose obras en él.

Sin embargo, su vida resultó bastante efímera. Este fabuloso conjunto fue destruido por el sultán alauí Mulay Ismail (1672-1727) quien con este acto no sólo aprovechó para llevarse muchos de sus materiales a Meknes, sino que con ello pretendía eliminar cualquier construcción que pudiera rivalizar con los palacios que estaba construyendo en su nueva capital. Así lo confirma, entre otras fuentes, un texto de J. B. Estelle que en 1698 nos da una clara referencia del proceso de destrucción y de las razones de ésta ${ }^{11}$.

Las ruinas del palacio fueron excavadas a mitad del siglo pasado por el arquitecto Regional de Monumentos Históricos A. Nolot, y por C. Allain ${ }^{12}$ sin que se llegara a publicar ninguna memoria de los resultados. Sólo disponemos de un plano de planta, realizado después de estas excavaciones y publicado por J. Meunier ${ }^{13}$.

Al-Badi' era en realidad la parte pública del palacio del sultán, destinada a las grandes ceremonias de audiencia y a los festejos de la corte, entre los que cabe destacar las celebraciones del mawlid, que más que a conmemorar el nacimiento del Profeta parecían estar destinadas a la mayor gloria del propio sultán, poniendo así en evidencia el principal objetivo buscado en la construcción de este conjunto ${ }^{14}$.

Debido a sus proporciones descomunales, y considerado como célula diferenciada dentro del conjunto residencial al que pertenecía, podemos afirmar que se trata sin duda del edificio áulico más grande que conocemos en el mundo islámico occidental, pues alcanza unas dimensiones de 155 x $130 \mathrm{~m}$. Todos los elementos que lo integran orbitan en torno a un patio de $150 \times 106$ $\mathrm{m}$ en el que agua y vegetación están presentes como verdaderos protagonistas acompañando a la arquitectura (Fig. 6). A lo largo de todo su perímetro se levantan

\footnotetext{
11 «Je tenois pour fabuleux ce qu’on m’avoit escrit de Miquenez, fait 3 mois, qui est que le roy de Maroc avoit envoyé des maçons à Maroc [Marrakech] pour mettre bas le fameux chasteau de cette dite ville et de faire transporter toutes les colonnes de marbre qui sont audit chasteau à Miquenez, ce qui a este executé. Ce jourd'huy 22 de novembre est arrivé en cette ville 9 charrettes chargées de tres belles colonnes de marbre, en nombre de 12, dont 4 estoient sysellées jusques au milieu et le restant de fleurs, ses pieds d'estail aussy bien travaillez... cependant le roy Mouley Ismail le fait abattre [le paIais du Badi' à Marrakech], ou pour le moins oster ce qu'il y a de beau et de bon, afin que celuy qu'il fait à Miquenez depuis 20 ans, qui est sans aucune beauté ni régularité, soit le plus beau qu'il y aye dans ses royaumes». (Estelle 1931: 385, citado por Barrucand 1985: 34).

12 Barrucand 1985: 115.

13 Meunier 1957: fig. IV.

14 Al-Ifrani 1889: 179.
}

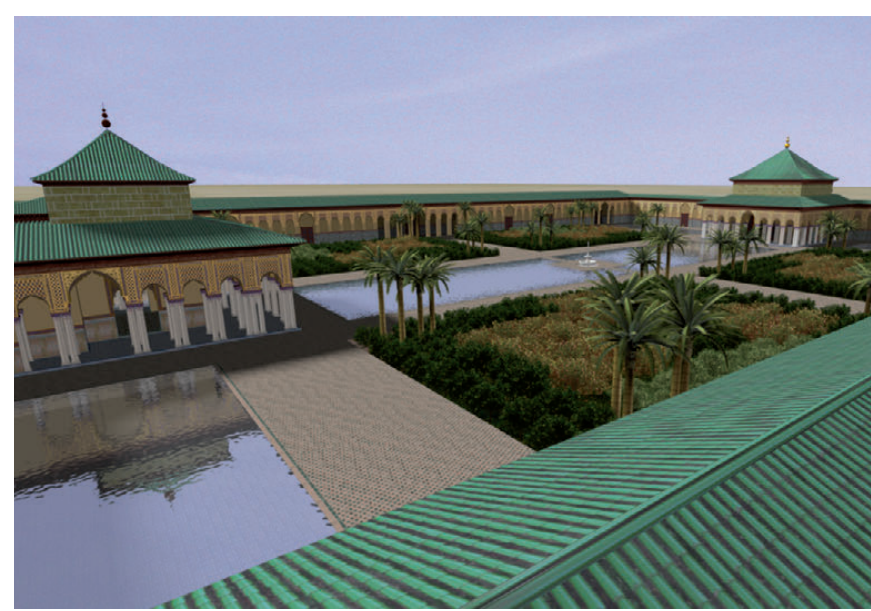

Figura 6. Visión reconstruida del palacio al-Badi' desde el noreste. (Imagen realizada por M. González y L. Berenguel sobre hipótesis de A. Almagro)

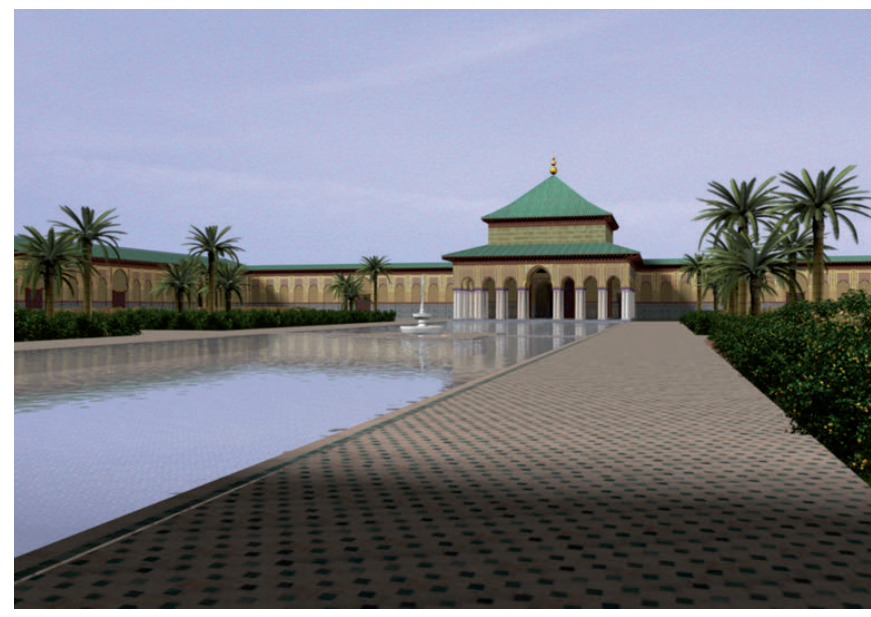

Figura 7. Vista de la alberca central y el pabellón occidental desde el este. (Imagen realizada por M. González y L. Berenguel sobre hipótesis de A. Almagro)

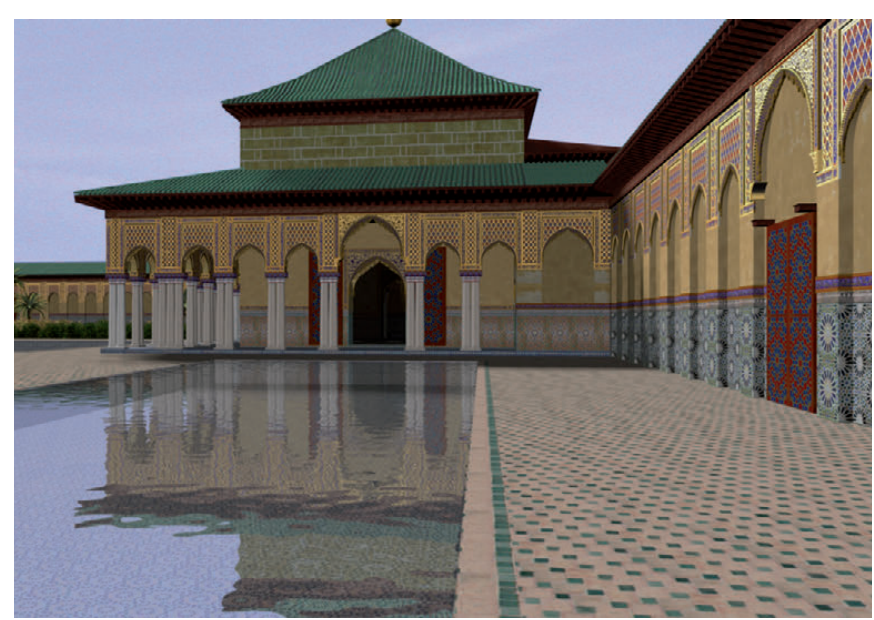

Figura 8. Vista del pabellón occidental desde el norte. (Imagen realizada por M. González y L. Berenguel sobre hipótesis de A. Almagro) 
crujías y pabellones que por el tamaño del conjunto adquieren dimensiones y aspecto que nada tienen que ver con las de otras construcciones anteriores o posteriores, aún cuando, como vamos a ver, los elementos que en él se integran y su ordenación son un claro reflejo de los modelos andalusíes, a los que sin duda su promotor buscaba dar continuidad como modo de legitimarse.

Elemento fundamental en la composición es una gran alberca de 90 x 20 m dispuesta en el eje mayor del patio que sigue aproximadamente la dirección este-oeste (Fig. 7). Esta alberca contiene en su centro una pequeña isla, que parece inspirada en la existente en uno de los grandes albercones de la cercana propiedad real del Agdal $^{15}$. Según documentos gráficos contemporáneos, parece que en ella hubo una fuente de doble taza ${ }^{16}$.

A ambos lados de la alberca hay cuatro grandes áreas de plantación de forma rectangular rehundidas respecto a los andenes (Fig. 2). La disposición del suelo de cultivo a más de dos metros de profundidad permite que la mayor parte de la vegetación, incluso arbórea, apenas sobresalga del nivel de los paseos que la rodean, facilitando de este modo la contemplación completa del conjunto sin interferencias visuales, a la vez que se logra una percepción de alfombra vegetal en una parte considerable de la superficie del patio ${ }^{17}$. A la zona cultivada se accede por escaleras dispuestas en los ángulos más cercanos al centro del patio. La separación entre las zonas de jardín se hace mediante amplios paseos, que estuvieron solados con azulejos, y que en la dirección longitudinal bordean también la alberca central, mientras en la transversal forman un a modo de crucero que no obstante, queda interrumpido por el estanque central, aunque estrechos puentecillos permitían cruzarlo a través de la isla antes mencionada. Acompañando a los parterres ajardinados y ocupando los cuatro ángulos del patio se dispusieron otras cuatro albercas que junto con la central rodean dos pabellones de los que hablaremos a continuación (Fig. 8).

Seguramente los elementos más distintivos de este conjunto lo constituían los dos pabellones con forma de qubba que se levantaban en el centro de los lados menores del patio. Sólo en el del lado occidental nos han llegado en pie los muros de su estructura principal, aunque nada de sus elementos ornamentales ni de su cubierta (Fig. 9). Del pabellón oriental únicamente se conserva su cimentación. Conocemos los nombres dados

\footnotetext{
15 El Faïz 2000: 30.

${ }^{16}$ Así puede interpretarse el dibujo de la figura 13 conservado en la Biblioteca del Escorial.

17 Almagro Vidal 2008: 254.
}

a ambos edificios: la Qubba al-Jamsiniya y la Qubba alDehbhiya $^{18}$. La primera sería la del lado occidental y su nombre aludiría a su dimensión de 50 codos, alrededor de 25 metros $^{19}$. El nombre de la segunda, la del lado oriental, haría referencia a los dorados de su decoración o incluso al sobrenombre del propio sultán, al-Dehbhi. Aunque para nuestro estudio nos hemos fijado de una manera especial en el pabellón occidental, único que conserva estructuras en alzado susceptibles de proporcionar información suficiente para plantear una hipótesis de reconstrucción, sí debemos indicar que el del lado oriental, a juzgar por el menor tamaño de su sala interior y por las indicaciones de alguno de los documentos gráficos de que disponemos, debió funcionar como espacio de contemplación y de acceso al jardín que se extendía, en un nivel inferior, al este del palacio, conocido como Arsat al-Ŷaŷ, y al que se descendía por una escalera desde el mismo pabellón.

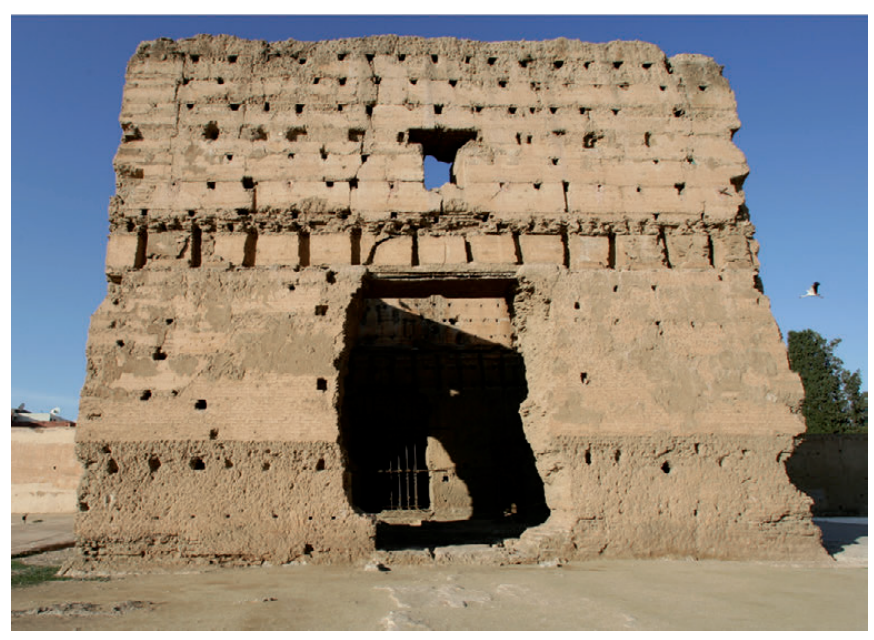

Figura 9. Frente oriental del pabellón occidental en 2005

En todo el perímetro del patio existían otras dependencias de muy diversa índole y entre ellas, algunas salas de gran importancia a juzgar por sus dimensiones y características. Aunque de momento aún no hemos dedicado nuestra atención a ellas, esperamos poder hacerlo en el futuro.

\section{EL PABELLÓN OCCI DENTAL}

En el presente trabajo vamos a analizar con detenimiento este pabellón ya que aunque se encuentra enteramente expoliado de todos sus elementos ornamentales y estructurales leñosos, como sucede con la totalidad

\footnotetext{
18 Deverdun 1959: 397.

19 Al-Ifrani 1889: 182. Esta dimensión se referiría al exterior del edificio que incluyendo los pórticos alcanzaba los 27.10 por $22.70 \mathrm{~m}$
} 
del conjunto, conserva casi por completo los muros que conformaban la sala interna que contienen gran cantidad de información merced a las huellas dejadas por la decoración que sobre ellos se dispuso y por las vigas y otras piezas que en ellos se empotraban. Gracias al estudio meticuloso de estos datos ha sido posible plantear una hipótesis para su reconstrucción que hemos llevado a cabo mediante imágenes de ordenador (Figs. 6-8).

La sala tiene unas dimensiones internas de $13 \times 13$ m (Fig. 10) y sus muros alcanzan actualmente una altura aproximada de 13 m también. Estos muros están compuestos por una masa de hormigón de cal vertida en los correspondientes moldes de madera según la técnica conocida como tapia. La obra de tapia quedaba delimitada en las jambas de los huecos mediante fábrica de ladrillo según un modo constructivo que es habitual en la arquitectura hecha con esta técnica. Se aprecia con claridad en todas las superficies de los muros los huecos dejados por las agujas de madera que servían para sostener los tapiales durante el proceso de vertido y apisonado de la masa, que en este caso no es de tierra sino de una mezcla de gravas, piedras, ladrillos y cal. Pese a la alteración de los paramentos a causa del expolio y destrucción de los tratamientos ornamentales, se aprecia hasta la altura del alicer la presencia de ladrillos dentro de la masa de tapia en un sistema que recuerda la denominada "tapia valenciana”, consistente en la colocación de ladrillos, a veces sólo simples fragmentos, como tizones dentro de la masa pero con uno de los lados cortos pegado a los tapiales y distribuidos de manera regular, aunque sin formar una auténtica fábrica de ladrillo ${ }^{20}$. Por encima de este nivel, la tapia es toda de argamasa. La cal está presente dentro de la masa del muro en muy alta proporción por lo que nos encontramos ante un verdadero hormigón de elevada resistencia, que además se ha comportado como muy durable en el tiempo pues pese a llevar más de trescientos años desprotegido sigue conservándose en razonable buen estado. El espesor de los muros es de $1.45 \mathrm{~m}$. Presentan en el centro de cada lado un gran hueco de acceso, que hasta hace poco estaban muy desfigurados (Fig. 4). De estos huecos, tres dan hacia el exterior mientras que el que mira a occidente da paso a una pequeña habitación que se comunica con otra contigua por el lado norte y a través de la cual puede salirse al patio. Hasta la reciente restauración, estos huecos presentaban una apariencia

\footnotetext{
${ }^{20}$ Este procedimiento permitía dar mayor adherencia a la costra externa del muro, que siempre se hacía más rica en cal, con el núcleo de éste que poseía menor concentración de conglomerante (Cristini y Ruiz 2012: 297-298).
}

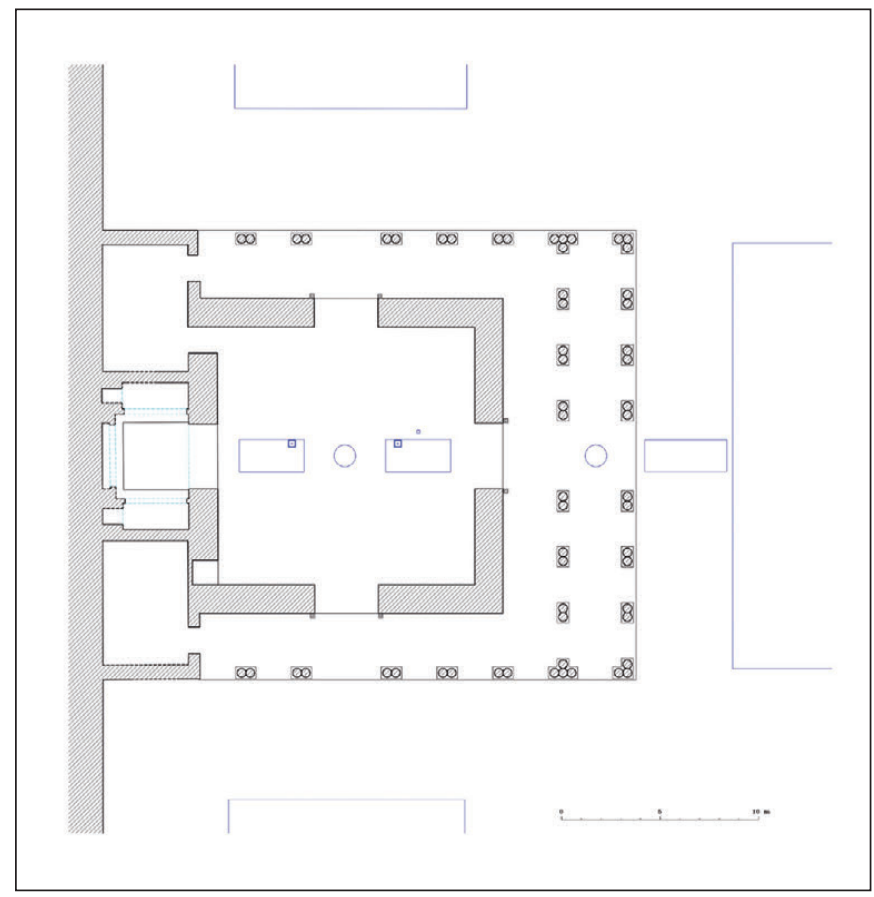

Figura 10. Planta reconstruida del pabellón occidental

amorfa debido a que sus jambas estaban construidas de ladrillo que mostraba enjarjes para su mejor trabazón con la obra de tapia. Al haberse expoliado los ladrillos, las jambas quedaron totalmente irregulares, lo mismo que la parte superior del hueco, por el desmoronamiento subsiguiente.

A pesar de todo, en la jamba derecha del arco de entrada del lado oridental, que corresponde al eje principal del pabellón, se ha conservado un pequeño resto in situ del pavimento junto con el arranque de la jamba (Fig. 11), lo que nos proporciona un dato preciso para conocer el nivel del suelo en el interior de la qubba y las dimensiones de los arcos, que eran de $3.30 \mathrm{~m}$ de luz. Además, por el exterior de este mismo arco aún pueden verse en el suelo las dos piedras con el orificio circular de las quicialeras de las hojas de madera con que se cerraba, lo que nos facilita una información fundamental respecto a la forma de clausura de la sala. Una cuestión que a nuestro juicio plantea serias dudas es la de si estos huecos tuvieron arcos estructurales de ladrillo o si por el contrario tenían dinteles de madera bajo los cuales se disponían arcos decorativos de lambrequines y mocárabes hechos de yeso y sin ninguna función portante, como es habitual en la arquitectura nazarí2 ${ }^{21}$. Creemos que la reciente restauración de estos huecos con arcos

\footnotetext{
${ }^{21}$ Almagro 2002: 183.
} 


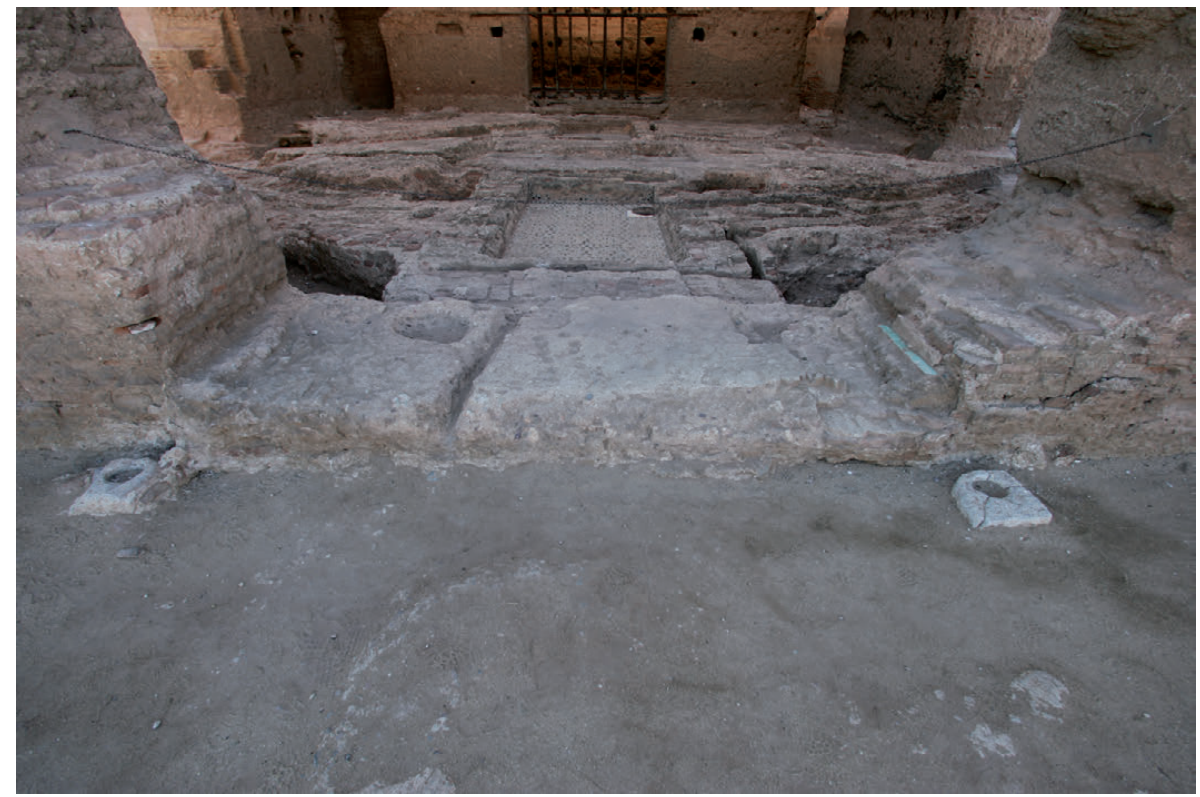

Figura 11. Hueco de acceso oriental al pabellón. Se aprecian las quicialeras de las puertas y un resto del pavimento del umbral junto a la jamba derecha en cerámica verde de ladrillo resulta totalmente desafortunada pues como hemos indicado, es muy posible que tuvieran dinteles de madera y en todo caso no debería haberse adoptado una solución basada en una hipótesis discutible.

En el lado oeste de la sala existen otras dos puertas más pequeñas, de $1.25 \mathrm{~m}$ de ancho, justo en los rincones, que tuvieron probablemente forma adintelada, pues conservan huellas de haber tenido cabeceros de madera. La del ángulo suroeste es en realidad una simple alacena que cabe suponer que tendría hojas que abrirían hacia la sala. La puerta del ángulo noroeste da paso a la habitación contigua a la situada al oeste de la qubba y de la que trataremos a continuación.

Esta habitación tiene aparentemente planta rectangular de 6.85 x $4.40 \mathrm{~m}$ y presenta actualmente huecos de paso en sus lados norte y este (Fig. 17). El del lado oriental es el hueco que comunica con el salón, similar a los que hay en el centro de cada uno de sus lados, mientras que el del norte parece fue una simple puerta que daba paso a otra habitación de dimensiones muy parecidas, aunque es muy posible que en origen este hueco no existiera, a juzgar por el tipo de fábrica que lo conforma que parece fruto de una actuación posterior. Constructivamente, ambos espacios fueron inicialmente uno sólo que luego se dividió mediante un muro de tapia de 0.57 cm de espesor, que presenta algunos elementos de ladrillo seguramente de una fase tardía. La primera habitación debió tener una planta aparente más compleja de lo que hoy vemos pues mediante elementos decorativos adosados se le dio aspecto de espacio centralizado con alhanías. Éstas resultan bastante evidentes en los lados norte y sur y es posible suponer su presencia también en el lado oeste donde tendría menor profundidad. Los datos que nos permiten plantear esta hipótesis son varios. En primer lugar la presencia de dos pilastrillas de ladrillo adosadas por el lado oeste del muro occidental de la qubba, de las que la del lado norte resulta plenamente visible mientras que de la simétrica sólo se aprecia la roza del muro en donde se empotraban parcialmente los ladrillos. En el muro frontero pueden verse las huellas de dos huecos, posteriormente tapados, que debían permitir el trabado de las paredes que confrontaban con las pilastrillas, lo que hace suponer la existencia de sendos arcos que delimitaban las alhanías. La anchura de éstas debió ser menor que la de la sala tal como hoy la vemos a juzgar por los rebajes realizados en los muros norte y sur, que nos dan una dimensión de 3.30 $\mathrm{m}$ de ancho por $1.60 \mathrm{~m}$ de profundidad. Podemos suponer que en el lado oeste había un arco semejante de la misma anchura pero de sólo $0.65 \mathrm{~m}$ de profundidad. Podemos pensar que este espacio se cubriría en la parte central con algún tipo de armadura de rica decoración y con pequeños alfarjes en las alhanías.

El suelo de la habitación presentaba dos niveles distintos, uno más bajo que debía estar a la misma cota que el salón o ligeramente más elevado y otro correspondiente a las alhanías que se encontraría un peldaño más alto. De este peldaño se conserva la traza de su tabica en los tres lados (Fig. 12).

La disposición de este espacio parece marcarlo como un lugar preeminente que podría indicar que la 


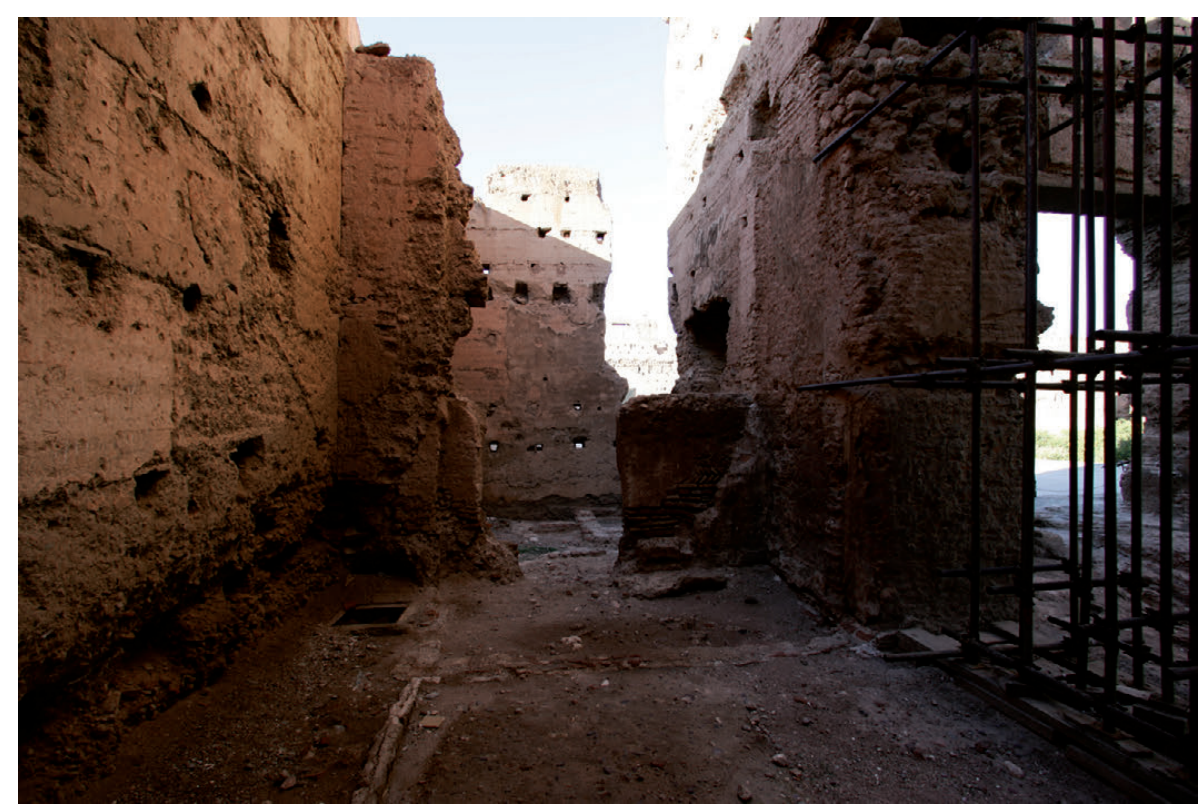

Figura 12. Vista de la pequeña habitación del lado occidental del pabellón habitación estaría destinada a ser el lugar en que se ubicaba el sultán, a semejanza del pequeño espacio de la ventana central del salón de Comares de la Alhambra en el que la epigrafía pone de manifiesto que era utilizado para este $\mathrm{fin}^{22}$. La disposición de dos albercas y una fuente dentro de la qubba hace imposible ubicarlo en ningún sitio del espacio principal. Sin embargo, el uso de un ámbito lateral para disponer el solio real permitiría además la colocación de una cortina, tras el arco, que ocultaba al soberano de la vista de sus súbditos, recurso ya usado por los califas omeyas y fatimíes y del que hay constancia que también utilizó al-Mansur ${ }^{23}$.

No sabemos si la habitación lateral comunicaba originalmente con la antes descrita, aunque sí lo hace con el salón a través de la puerta que se abre en su ángulo noroeste y cabe la posibilidad que también lo hiciera con el pórtico que rodea la qubba. En sus muros aparecen huellas de distinto tipo. En el lado norte encontramos mechinales de gruesas vigas que nos indican que no tuvo mucha altura. Y que muy posiblemente hubo una planta alta. Esto lo corroboraría la existencia de una roza en el paramento oeste que pudiera ser la huella de una bóveda que sostuviera uno de los tiros de la escalera. De todos modos, el hecho de que la atarjea de desagüe de la fuente y las albercas del salón pase por aquí, permite igualmente suponer que al menos parte de la habitación contuviera una letrina. Sería necesaria una limpieza cuidadosa del suelo de este espacio para poder disponer de más información.

\footnotetext{
22 Orihuela 1996: 89.

23 García Arenal 2009: 118-119.
}

El espacio principal de pabellón occidental es uno de los pocos lugares en que la excavación del subsuelo ha quedado visible permitiendo observar la compleja disposición de las redes hidráulicas que abastecían y drenaban la fuente y las dos alberquillas que hay en el interior y cuyo levantamiento nos ha permitido interpretar el funcionamiento de todo el sistema.

Por ligeros indicios aún visibles alrededor del pabellón, por referencias dibujadas en el plano de la excavación y por el testimonio que nos aportan distintos documentos gráficos de la época ${ }^{24}$ (Figs. $3,15,16$ ), sabemos que la qubba estaba rodeada en tres de sus lados, por un pórtico sostenido por columnas y que era de doble crujía en el frente. Dentro de este pórtico frontal había una fuente circular y delante de él una alberquilla rectangular de dimensiones parecidas a las de las existentes en el interior.

El análisis de los paramentos y la experiencia y conocimiento de las pautas ornamentales y métodos constructivos usados en la arquitectura andalusí ha permitido identificar las huellas que los distintos materiales y sistemas decorativos habían dejado (Figs. 4, 13). Así, en la parte baja de los muros se aprecia un ligero picado de la superficie del paramento para facilitar la adherencia del mortero de agarre de los zócalos de alicatado. A una altura de aproximadamente $2.25 \mathrm{~m}$ el paramento vuelve a ser liso pues el yeso de la decoración labrada no tenía dificultades de adherencia y agarre. A $6.35 \mathrm{~m}$ de altura, tanto en el exterior como en el interior, aparecen los huecos deja-

\footnotetext{
${ }^{24}$ Vid. infra, notas 27 y 29
} 


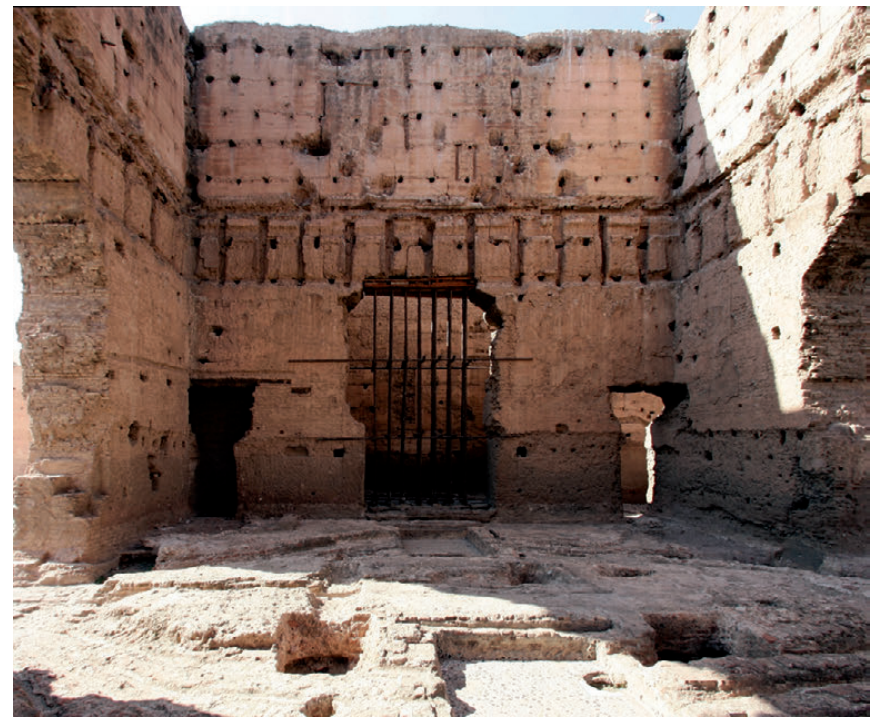

Figura 13. Paramento interior del lado occidental del pabellón en 2005

dos por una serie de rollizos verticales que se empotraron en la masa del tapial cada $1.20 \mathrm{~m}$ aproximadamente y que servían para fijar sobre ellos los tableros que conformaban el arrocabe de madera labrada y policromada.

En los paramentos exteriores, por encima de la huella del arrocabe, se aprecian los huecos en que se empotraban las vigas del techo del pórtico. Algo más arriba hay otra serie de huecos algo más irregulares que corresponden a los pares de la estructura de la cubierta que pudieron haber estado constituidos por rollizos. De esta forma quedan perfectamente definidas todas las alturas de los distintos paños decorativos externos. Entre el nivel del alfarje del pórtico y el de apoyo de los pares de la cubierta aparecen en los tres muros de los lados norte, este y sur, unos huecos rectangulares de 1.10 x 1.40 m que permitían comunicar el espacio bajo cubierta de la zona de los pórticos con el existente sobre la armadura de la qubba. En el muro meridional, por encima del nivel de apoyo de los pares de la cubierta del pórtico, existe otro hueco de 0.75 x $1.00 \mathrm{~m}$ que serviría para poder acceder al tejado desde este último lugar, facilitando el mantenimiento de la cubierta.

Por el interior, en donde el arrocabe es mucho más alto, las huellas de vigas adoptan por encima de aquél una disposición distinta. En concreto, a una distancia de las esquinas equivalente a un tercio aproximadamente de la longitud del lado de la sala, se observa en todos los paramentos interiores de la qubba la presencia de huecos de empotramiento de vigas en disposición diagonal, uniendo los dos muros contiguos a cada esquina (Fig. 13). La presencia de estos huecos se repite a tres niveles distintos.
Estas vigas en diagonal o cuadrales, nos indican con toda claridad que la sala se cubrió con una armadura ochavada cuyos estribos octogonales apoyarían en estas vigas ${ }^{25}$.

Es de suponer que los muros se rematarían con el correspondiente alero de canecillos de madera que quedaría anclado mediante un remate de fábrica de ladrillo que se asentaría sobre la obra de tapia y que hemos de presumir expoliado al igual que otros elementos hechos de igual modo.

Para establecer la hipótesis sobre la forma y apariencia original de este pabellón disponemos, además de la información que nos proporcionan las estructuras conservadas, de dos testimonios gráficos contemporáneos al edificio que nos aportan datos de enorme utilidad. El primero de ellos es el dibujo realizado por el fraile trinitario Antonio de Conçeyçao, adjunto a un informe remitido a Felipe II sobre el martirio sufrido por siete jóvenes cristianos en 1585 por orden de Ahmad al-Mansur, y que se conserva en la biblioteca de El Escorial $^{26}$. El dibujo, que cuenta con el interés de estar realizado a color (Fig. 14), nos ofrece una descripción de la qasba sa'adí llena de ingenuas representaciones pero de fácil interpretación gracias al realismo con que se muestran. Para lo que más nos interesa del pabellón occidental, podemos destacar los siguientes detalles:

a. La qubba está rodeada en sus tres lados exentos por pórticos formados por arcos sostenidos sobre columnas, prolongados en sebka y con un vano central de mayor tamaño con arco de lambrequines.

b. El pórtico se cubre con tejado de tejas verdes a la misma altura que todas las construcciones del perímetro del patio.

c. Por encima de este tejado sobresale la parte alta de la qubba que presenta un aparejo de grandes sillares, seguramente fingido sobre la obra de tapia, tratamiento muy habitual en este tipo de construcción.

d. El cuerpo de la qubba se cubre con un tejado de pabellón a cuatro aguas rematado con un yamur a base de esferas doradas ${ }^{27}$. El tejado es también de tejas verdes.

e. El pavimento de los andenes del patio está formado por azulejos cuadrados de colores variados y alternos.

Dejamos de lado otros muchos detalles que para el objetivo limitado que nos hemos propuesto no tienen relevancia.

\footnotetext{
${ }_{25}$ Nuere 1989: 72-81.

${ }^{26}$ Biblioteca de El Escorial, no sign. d.III.27; Koehler 1940.

${ }^{27}$ Este tipo de remate suele ser común y casi exclusivo de las mezquitas y alminares, aunque el dibujo en este caso no deja lugar a dudas.
} 

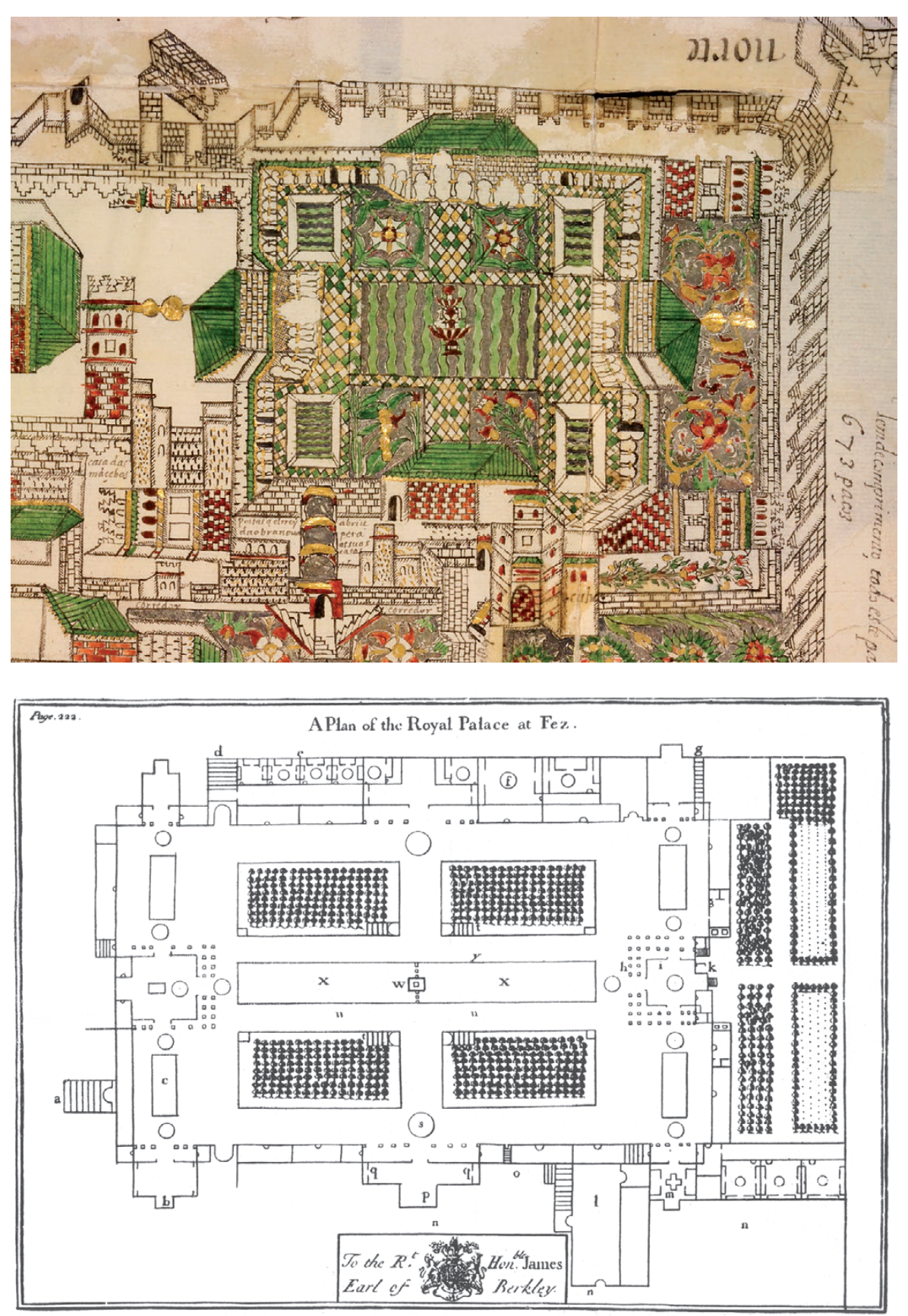

Figura 14. Detalle del dibujo conservado en la Biblioteca del Escorial representando el palacio al-Badi'. (c) Patrimonio Nacional
Figura 15. Planta del palacio al-Badi dibujada por Jacob Gool en 1623 (reproducida de Meunier 1957)
La otra imagen corresponde a un plano esquemático pero bastante bien proporcionado y detallado (Fig. 15), dibujado en 1623 por el ingeniero holandés Jacob Gool, o Golius, y publicado por John Windus en $1725^{28}$. También en este caso nos interesan los detalles siguientes:

\footnotetext{
${ }^{28}$ Windus 1725: 222, reproducido en Meunier 1957: fig 1. Aunque el plano aparece rotulado como Palacio Real de Fez, no cabe duda de que se trata de un error, bastante común en ediciones de viajes de esa época en que la falta de memoria de sus autores y la imposibilidad de control de los editores por desconocimiento, producía este tipo de equivocaciones. Algo parecido puede verse en la publicación de los planos del Cuarto Real de Santo Domingo por Murphy, que aparece rotulado como si correspondieran al Generalife (Murphy 1813).
}

1. El pórtico perimetral es de una sola crujía en los laterales pero doble en el frente. Un vano de cada pórtico, que coincide con las puertas de la qubba, es mas ancho, tal y como también aparece en el dibujo de El Escorial.

2. Aunque con algunos errores, se representan con bastante exactitud puertas y escaleras así como las fuentes y albercas del interior de las salas y los pórticos, corroborando y completando en parte la información que da el propio suelo actual del palacio.

3. Con toda esta información hemos podido plantear la hipótesis representada en los planos y dibujos que 


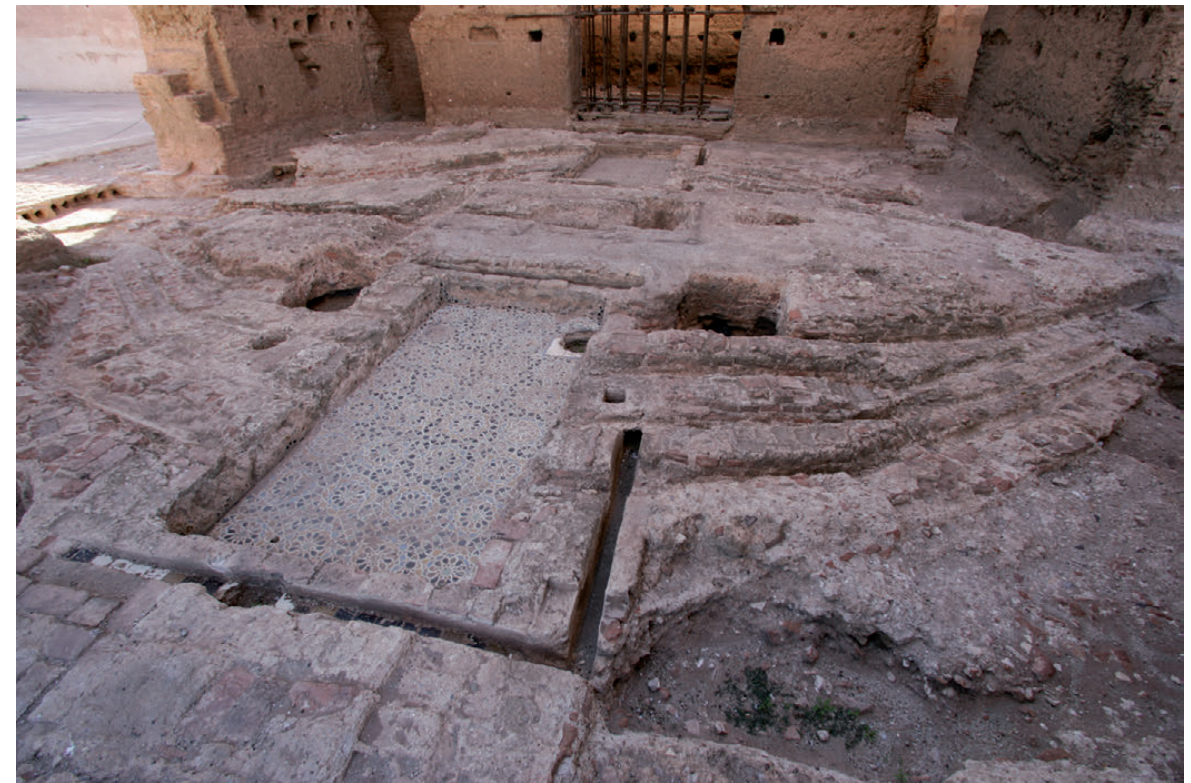

Figura 16. Vista del suelo actual del pabellón occidental mostrando los restos del sistema hidráulico publicamos (Fig. 10, 25-27) y sobre la que volveremos más adelante.

\section{EL SI STEMA HI DRÁULI CO}

Una atención especial merece a nuestro entender el análisis de los restos conservados en el suelo de este pabellón y que tienen relación fundamentalmente con el sistema hidráulico que abastecía y drenaba la fuente y albercas ubicadas en su interior. Todo el suelo actual del pabellón se nos presenta como el resultado del expolio producido en el edificio que produjo la desaparición de los pavimentos y de una parte considerable de las canalizaciones de agua (Fig. 16). No obstante, al estar éstas embutidas en una masa de calicanto de gran resistencia, han dejado abundantes restos adheridos y muchas huellas que nos permiten conocer cómo estaba dispuesto el sistema de suministro y evacuación de agua. Hay que advertir que en este suelo también se aprecian huecos y rozas que parecen corresponder a usos del edificio posteriores al expolio.

Dentro del pabellón se dispusieron dos pequeñas albercas rectangulares, alineadas con el eje principal y una fuente que ocupaba su centro geométrico. De la fuente no tenemos más datos que la huella de la tubería de llegada del agua y la canalización de desagüe, pero no ha quedado ningún testimonio ni de su forma ni de los materiales de que estaba hecha. De las albercas, sin embargo, se ha conservado su pavimento casi íntegro y restos del recubrimiento de sus paredes, así como las huellas de las tuberías de abastecimiento y las conducciones de desagüe prácticamente intactas. Todo esto nos permite conocer con bastante precisión cómo pudo funcionar el sistema hidráulico, que hemos de considerar resultaba bastante sofisticado (Fig. 17).

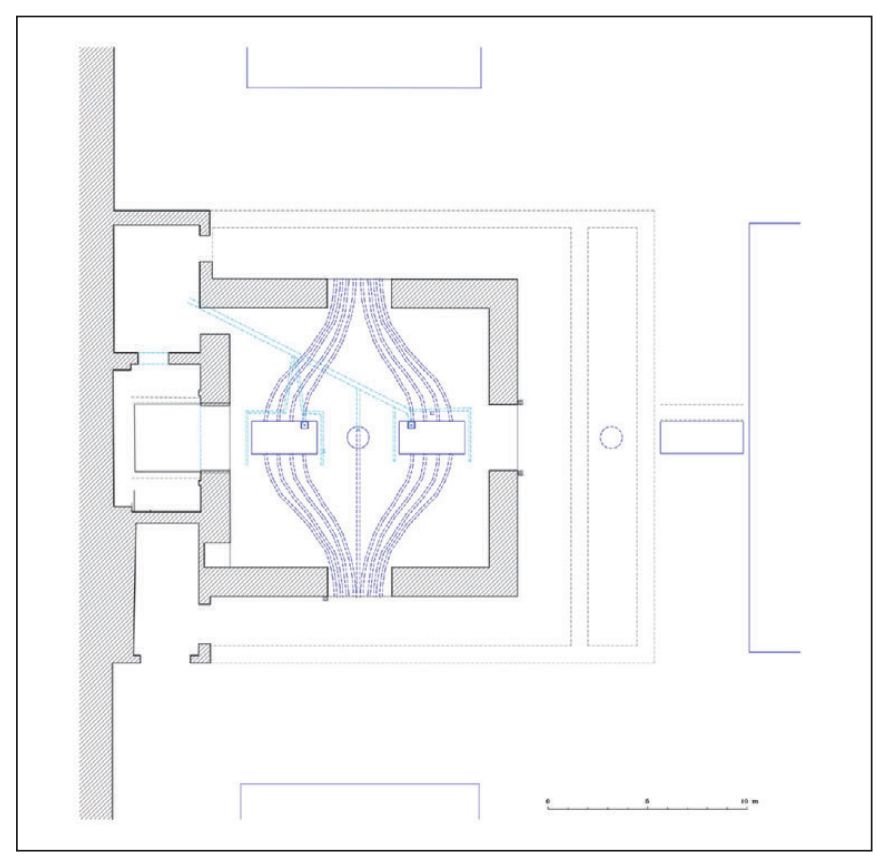

Figura 17. Planta actual del pabellón occidental con las distintas canalizaciones del sistema hidráulico (Se incluyen como hipótesis las columnas del pórtico)

Las dos albercas son de dimensiones idénticas, de 1.65 x 3.29 m y 0.65 m de profundidad, ocupando ambas una posición inmediata a los arcos de acceso por el este y el oeste. Estuvieron revestidas por un fino alicatado que presenta motivo de lazo de ruedas de 12 con 
cinta blanca y zafates, sinos, almendrillas y candilejos en colores negro, verde melado y azul. Cerca del ángulo del lado norte más cercano al centro de la sala aparecen en el pavimento de ambos estanques unas placas de mármol con un orificio en el centro que servían de desagües pues hasta ellas llegan las atarjeas dipuestas para esta función. No sabemos si estos desagües eran utilizados únicamente para vaciar completamente las alberquillas cuando se fueran a limpiar o si servirían también de aliaviaderos para la circulación permanente, en cuyo caso deberían tener algún sistema de regulación del paso del agua, o quizás se adaptarían en ellos unos tubos verticales que funcionaran como rebosaderos.

No obstante, parece más probable que tal función de rebosadero se realizara a través de los canalillos que, al menos en tres lados, bordean ambas albercas. El hecho de que haya desaparecido el pavimento de la sala junto con la base en que se asentaba en un espesor de casi 35 cm nos impide saber cómo era el remate de los bordes de las albercas y cómo se resolvían detalles importantes como el del rebosado del agua sobrante, que bien pudo hacerse mediante orificios situados en la parte superior de las paredes que comunicarían con los canalillos mencionados, que muy posiblemente quedaban cubiertos por el pavimento, pues hay indicios de ello.

Estos canalillos, o más bien pequeñas atarjeas perimetrales, se unen con la que recoge el desagüe de fondo en una atarjea principal que lleva dirección diagonal y se dirige hacia la puerta del ángulo noroeste de la sala, por donde salía toda el agua sobrante. Aunque las albercas tienen una disposición totalmente regular y simétrica, las atarjeas no, pues el hecho de que su salida se realice por un ángulo provocó que se adoptaran recorridos irregulares. En todo caso, la hipótesis de cómo funcionaba el sistema de desagüe hay que contemplarla en relación con la llegada del agua.

Ésta se realiza por el suelo, a través de los dos arcos de acceso a la qubba por los lados norte y sur. No sabemos por donde llegaba el agua hasta estos puntos, aunque lo más seguro es que se hiciera desde la zona sur del palacio, pues es por ese lado por donde llegaba el acueducto que se abastecía de algunas de las jetara-s o kanat-s con que se procuraba una parte sustancial del abastecimiento de Marrakech. El hecho es que en el subsuelo de ambos huecos encontramos seccionadas una serie de conducciones construidas mediante atanores cerámicos. Aunque no se ha excavado en la zona exterior, todo parece indicar que las canalizaciones se encuentran casi intactas en esa parte, mientras que en el interior fue- ron sistemáticamente arrancadas, pese a lo cual se puede seguir su trayectoria gracias a las improntas dejadas en la masa de calicanto en que estaban embutidas y que ha desaparecido en su parte superior pero que se conserva bastante intacta en lo que sería el lecho de apoyo de todo el sistema.

En el arco meridional pueden observarse nueve tuberías mientras en el norte solo hay ocho. Esto se debe a que la conducción central del lado sur era la que abastecía la fuente del centro de la sala, lo que nos permite insistir en que la llegada general de agua era por ese lado. Los conductos del lado norte deben provenir de un repartidor que estaría alimentado por una canalización que se debió hacer trascurrir por el exterior de la sala para no interferir con el complejo sistema de tuberías dispuesto en el interior, pero cuyo recorrido desconocemos. Las otras ocho tuberías se dividían dentro del salón en dos grupos dirigiéndose hacia los lados meridionales de ambas albercas a las que acometen con espacios de separación regulares. Los ocho atanores que entran por la puerta septentrional llevan un recorrido simétrico a los antes descritos desembocando por el costado norte de ambas albercas (Fig. 18). El hecho de que todas las conducciones discurran por el pavimento a cierta profundidad y que su huella se aprecie hasta muy escasa distancia de los bordes de las albercas hace pensar que el agua se introducía en éstas por las paredes de los lados norte y sur, seguramente mediante toberas situadas a unos $25 \mathrm{~cm}$ por debajo del borde, lo que permite suponer que probablemente lo hacía por debajo del nivel de la superficie del agua. Naturalmente, esto dependería de la cota a la que se encontraran los rebosaderos, pero habida cuenta de que en las paredes no hay huella alguna de ellos por debajo de las que existen de las tuberías de abastecimiento, nos inclina a pensar que se encontraban más altos. Dado que sólo hay atarjeas de desagüe en los lados este, oeste y norte, pero que además en éste último no tienen continuidad, podemos deducir que la salida del agua de las albercas se producía por los lados este y oeste, al contario que la entrada que lo hacía por el norte y el sur.

La pregunta que surge de inmediato es ¿qué efectos produciría esta disposición de entrada y salida del agua? En primer lugar hay que afirmar que el primero sería el de que el observador no sabría cómo circulaba el agua ${ }^{29}$.

\footnotetext{
${ }^{29}$ Este dispositivo parece muy similar al que suponen Darío Cabanelas y Antonio Fernández Puertas para la fuente de los Leones de la Alhambra (Cabanelas y Fernández 1981: 6, 29-30).
} 


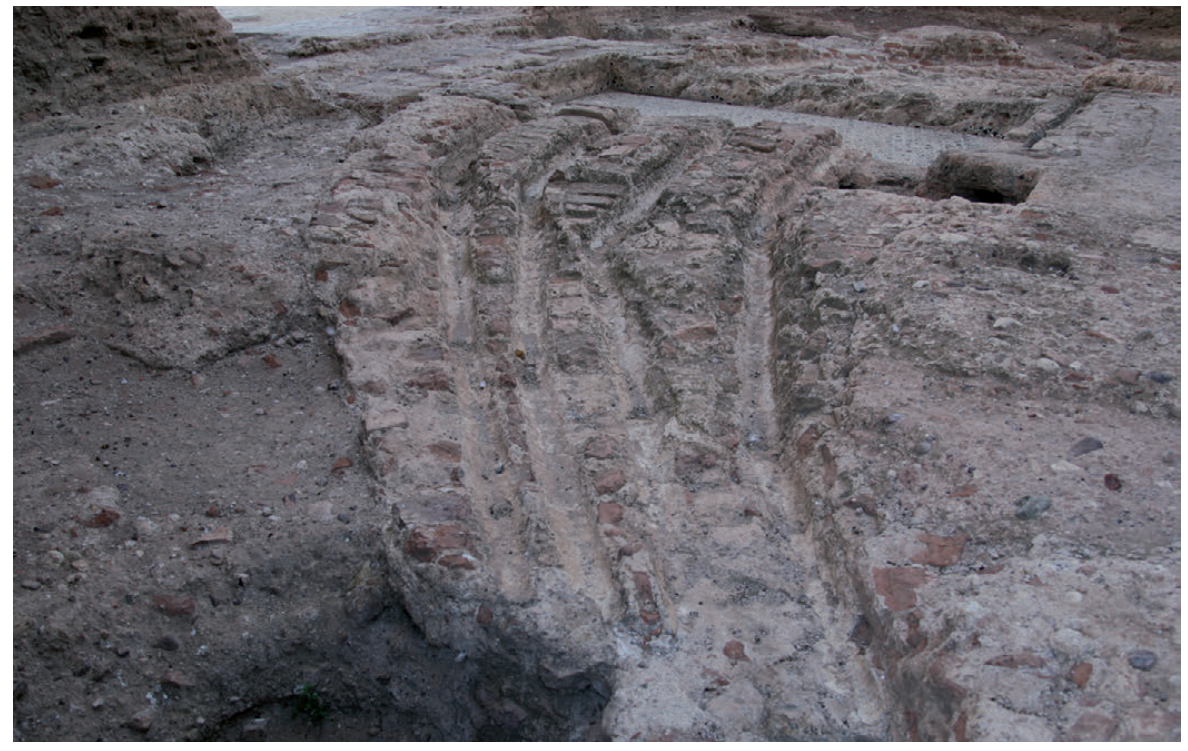

Figura 18. Huella de las canalizaciones que abastecían la alberquilla occidental por el lado norte
Como ésta debía entrar con cierta presión se tenía que producir un movimiento en la superficie que debía resultar inexplicable al no verse ningún chorro ni canal de llegada. La ondulación de la superficie produciría, por efecto de la reflexión de la luz que entraba por las puertas, efectos de iluminación dinámica dentro del espacio de la sala en el que hay que imaginar que las superficies doradas se extendían por doquier ${ }^{30}$ produciendo nuevas reflexiones, lo que contribuiría a generar una sensación de espacio mágico e irreal provocando sin duda la admiración y sorpresa en los visitantes.

La fuente que se ubicaba en el centro de la sala debía de ser circular, seguramente con taza de mármol o de otra piedra de calidad como el onix, de las que sabemos por los textos de su existencia ${ }^{31}$. Tendría seguramente un pequeño surtidor central que añadiría un murmullo de agua en movimiento complementando con este sonido la ambientación del espacio. La presencia de estos elementos de agua dentro de la sala provocaría también una sensación de frescor ayudando a la climatización del ambiente.

En suma, cabe decir que mediante un sofisticado sistema de manejo del agua se lograba a la vez una ambientación climática, pero sobre todo de percepción visual del espacio que contribuía poderosamente al logro de los objetivos que el promotor de esta magna obra se había propuesto: la creación de una arquitectura que no sólo por sus dimensiones colosales sino por el refinamiento en el usos de determinados recursos como el agua o la luz, generaran en el visitante efectos sorpresivos que le llevaran a una

\footnotetext{
${ }^{30}$ Al-Ifrani 1889: 181.

${ }^{31}$ Al-Ifrani 1889: 181.
}

actitud de admiración y finalmente de sumisión y respeto ante el soberano que habitaba tan mágicos espacios ${ }^{32}$.

Aunque a través de las imágenes de ordenador hemos tratado de recrear algunas de estos efectos, hemos de reconocer que la tecnología hasta ahora disponible por nosotros no nos permite provocar las sensaciones lumínicas que sin duda se podían contemplar y que en todo caso tendrían que apreciarse dentro de una observación dinámica del espacio ${ }^{33}$. Deberá seguir siendo nuestra imaginación la que supla nuestras carencias técnicas.

\section{PARALELOS}

El palacio al-Badi' es sin lugar a duda una consecuencia de la evolución de la arquitectura de al-Andalus. Tanto la forma general del edifico como los distintos elementos que lo forman tienen claras raíces y precedentes en lo construido por los califas y soberanos musulmanes en la Península Ibérica ${ }^{34}$. La disposición general del inmueble, organizado en torno a un patio concuerda con la de la

\footnotetext{
32 Algunos de estos efectos pueden estar narrados en los poemas que aparecían escritos en los paramentos del salón y que en parte están recogidos en al-Ifrani 1889: 179-195.

${ }_{33}$ En la recreación animada que hemos realizado y que puede verse mediante un DVD (Almagro 2012), resultó imposible introducir la reflexión de la luz en la superficie en movimiento del agua pues el programa 3D-Studio generaba efectos inaceptables para la realidad.

${ }^{34}$ Desgraciadamente son casi inexistentes en Marruecos los ejemplos de arquitectura áulica anterior a este palacio de los que tengamos información ya que en general han sido destruidos o transformados. De los que sería más interesante tener noticias en relación con este caso, los de época meriní, apenas sabemos nada, ni siquiera si puede haber restos de ellos en dentro del actual palacio real de Fez al-Yadid, cuya construcción se inició apenas unos años después de la Alhambra. Sabemos que en sus jardines había estanques y pabellones (Bressolette y Delaroziére 1978-1979).
} 
mayoría de los edificios áulicos andalusíes ${ }^{35}$. La organización del área del patio, por su parte, representa también una clara continuación de los modelos andalusíes aunque con innovaciones que en parte pueden deberse a las necesidades impuestas por la escala monumental adoptada.

La presencia dentro del patio de un gran estanque en el eje de la composición nos muestra una continuidad con los esquemas que se imponen en el período nazarí, a partir de finales del siglo XIII, y que ya están presentes en el período de transición desde lo almohade, en la primera mitad de ese siglo, como es el caso del Qasr al-Sagir, en el actual Convento de Santa Clara, de Murcia ${ }^{36}$, conjunto con el que comparte también otras similitudes (Fig. 19). El más claro exponente de este tipo de composición es sin duda el patio de Comares de la Alhambra, donde la gran alberca bordeada por dos pequeños parterres plantados de arrayán confiere la fisonomía característica al conjunto conformando un gran espejo en el que se refleja la arquitectura que la circunda, $y$ especialmente la de los lados menores en donde no existe jardín separador ${ }^{37}$.

Sin embargo, en el caso granadino, desaparece totalmente el esquema de crucero que sigue presente en el palacio de Marrakech, manteniendo una tradición de siglos anteriores que en el período nazarí parece olvidarse, aunque también resurgirá en los palacios de los Leones y de Alijares. El patio de crucero está ya implícito en el jardín alto de Madinat al-Zahra y plenamente implantado en su jardín bajo ${ }^{38}$. En el siglo XII, en el Castillejo de Monteagudo $^{39}$ tenemos un patio con jardín de crucero, albercas con agua en el eje y parterres de jardín rehundidos, es decir, todos los ingredientes que vemos siguen presentes cuatro siglos después. En el Qasr al-Sagir de Murcia (Fig. 19) aparece seguramente la disposición más parecida a la de al-Badi', con cuatro parterres rehundidos separados por un anden de crucero que queda interrumpido por una gran alberca longitudinal ${ }^{40}$.

Algo más tarde, a finales del siglo XIII, encontramos también un patio de crucero con alberca central en el Alcázar Real de Guadalajara ${ }^{41}$. Pero no sólo podemos citar como precedente de patio de crucero con alberca o fuente central el caso del palacio de los Leones y los otros antes citados. También resulta de sumo interés comparar este palacio de Marrakech con el desaparecido palacio de la almunia de los

\footnotetext{
35 Torres Balbás 1958: 187.

36 Almagro 2008: 51-52.

37 Almagro Vidal 2008: 301.

38 Almagro 2007a: 57, 61.

39 Navarro y Jiménez 1995, Almagro 2008: 43-44.

40 Almagro 2008: Fig. 25.

41 Almagro 2008: 72-76.
}

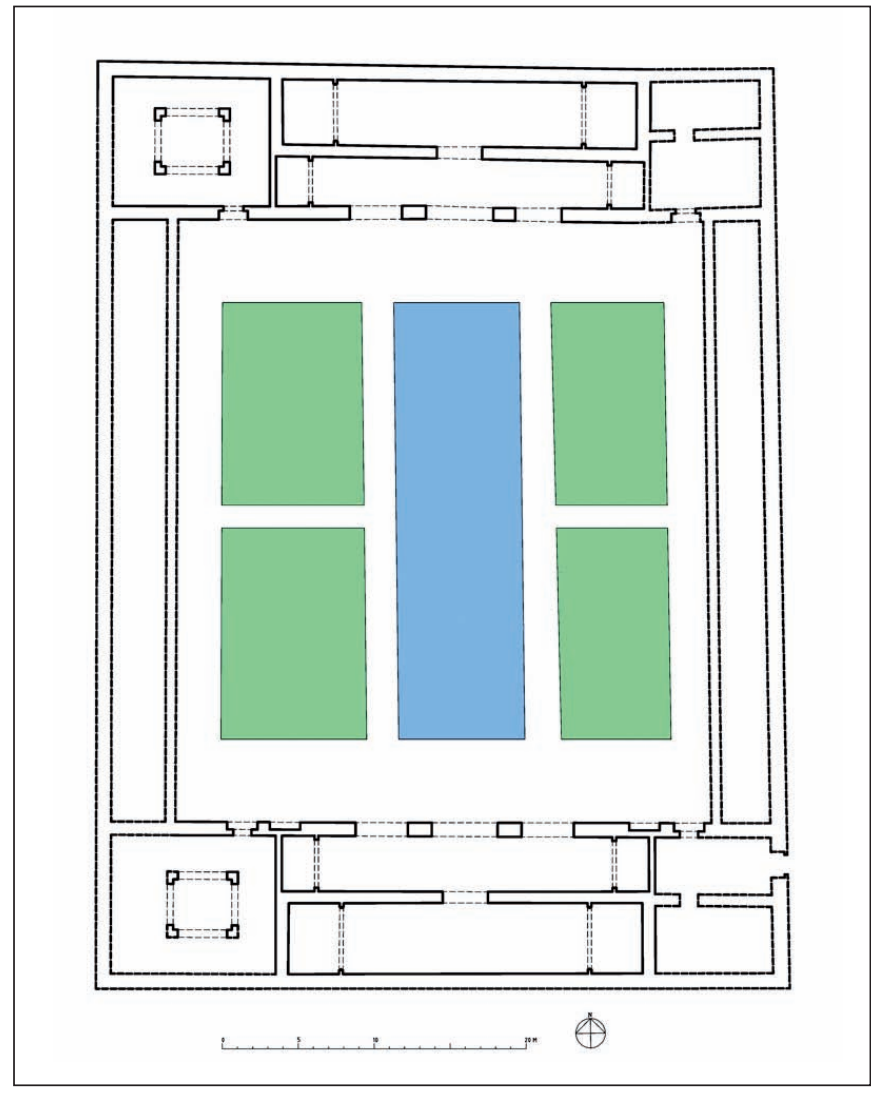

Figura 19. Planta del Qasr al-Sagir en el convento de Santa Clara de Murcia

Alijares, en los alrededores de la ciudad de Granada. Según la hipótesis de reconstrucción recientemente realizada ${ }^{42}$ tendría una alberca central y cuatro pabellones con forma de qubba en los extremos de los andenes del crucero, en el centro de cada lado del patio. Esto último guardaría relación con la disposición de al-Badi', en donde además de los pabellones prominentes hacia el jardín existían otros dos salones o espacios de mayor categoría en el centro de los lados largos del patio.

La alberca del palacio marroquí presenta la particularidad de la presencia de una pequeña isla en la que, según la documentación disponible, sabemos había una fuente. La disposición de una isla en medio de una alberca la encontramos en época almohade tanto en alAndalus, caso del estanque de la huerta de la Cartuja de Nuestra Señora de las Cuevas de Sevilla, como en el que pudo inspirar más directamente la solución adoptada en al-Badi', que sería el de la alberca al-Ghrisiyya de la cercana almunia real del Agdal.

Las dos albercas que en cada lado ocupan los ángulos del patio y que junto con la central rodean los dos

\footnotetext{
42 García Pulido 2013: 233-236.
} 
pabellones, forman una disposición que recuerda la del pabellón central del jardín alto de Madinat al-Zahra, primer ejemplo de este tipo de jardín con presencia de amplias áreas de vegetación y extensas albercas que además de servir para el riego permitían un control climático y provocaban visiones espectaculares al actuar como espejos en los que se reflejaba tanto la arquitectura como la luz que penetraba en ella ${ }^{43}$.

Los jardines rehundidos tienen una larga tradición en al-Andalus. Ya en Madinat al-Zahra, con la disposición de andenes a distinto nivel en el jardín alto, junto a los grandes salones de recepción, se persigue la idea de "caminar sobre la vegetación", que adquiere así la función de alfombra. El tema toma mayor relevancia en época almohade, cuando se construyen algunos ejemplos notables como es el caso del Patio del Crucero del Alcázar de Sevilla ${ }^{44}$, en el que el jardín ocupa un nivel totalmente distinto del resto del palacio, a más de cuatro metros por debajo de éste. Otros casos como el de la Casa de Contratación ${ }^{45}$, también perteneciente al Alcázar sevillano, ofrecen soluciones intermedias (Fig. 20). En este caso resulta también llamativa la presencia del agua en el eje del patio con una fuente en su centro, de la que apareció en la excavación la huella de su apoyo.

La presencia de los dos pabellones prominentes hacia el centro del patio nos trae inmediatamente a la memoria la disposición semejante que hay en el Patio del Qasr alRiyad al-Sa'id (Palacio del Jardín Feliz) ${ }^{46}$ hoy conocido como Patio de los Leones de la Alhambra (Fig. 21), aunque salvando las enormes diferencias de tamaño de ambos conjuntos $^{47}$. El uso de tal disposición de pabellones prominentes en los extremos del patio y con unas proporciones más cercanas al precedente nazarí ya había sido aplicado en este mismo período al construir los dos pabellones del sahn de la mezquita al-Qarawiyyin de $\mathrm{Fez}^{48}$, lo que confirmaría ese casi obsesivo recurso a los modelos de alAndalus durante el período que nos ocupa.

Sin embargo, los pabellones de este palacio de Marrakech tienen unas características especiales que una vez más están en gran medida motivadas por la escala colosal del conjunto. No se trata en este caso de sencillos kioscos para albergar una fuente o para ser meras protuberancias de los pórticos del patio, sino que constituyen grandes

\footnotetext{
43 Almagro 2007a: 58, 61, 62.

44 Almagro 1999: 343-344.

45 Almagro 2007b: 190-195.

46 Fernández Puertas 2006: 112-121.

47 Orihuela 1996: 103.

48 Marçais 1954: 387.
}

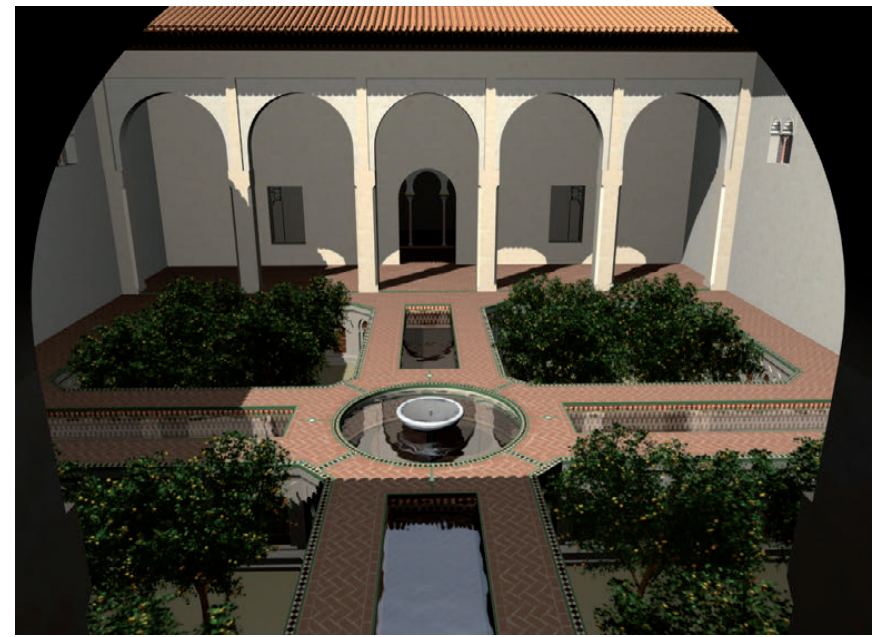

Figura 20. Patio de la Casa de Contratación del Alcázar de Sevilla en época mudéjar. (I magen realizada por M. González sobre hipótesis de A. Almagro)

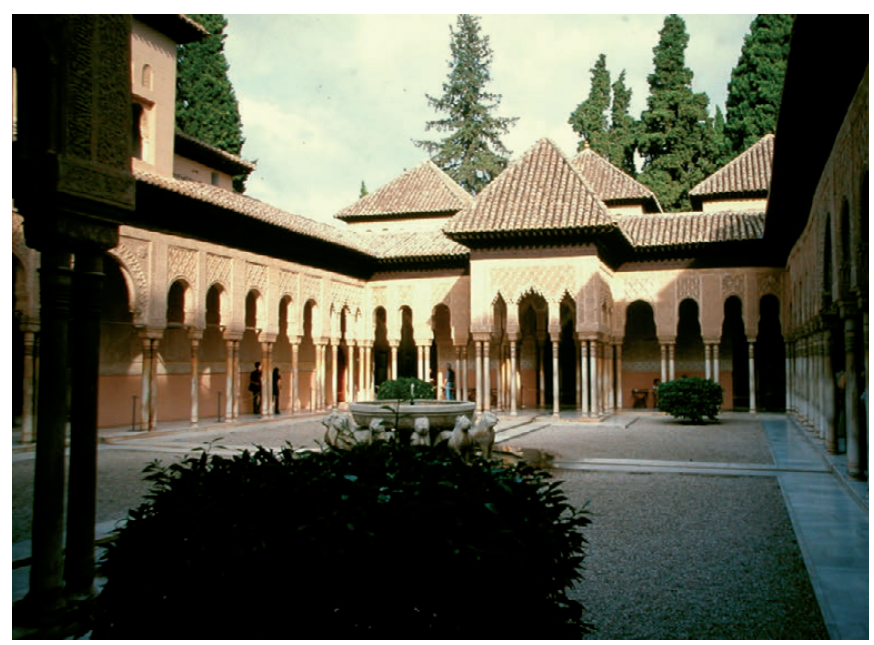

Figura 21. Vista del Patio de los Leones con sus pabellones prominentes

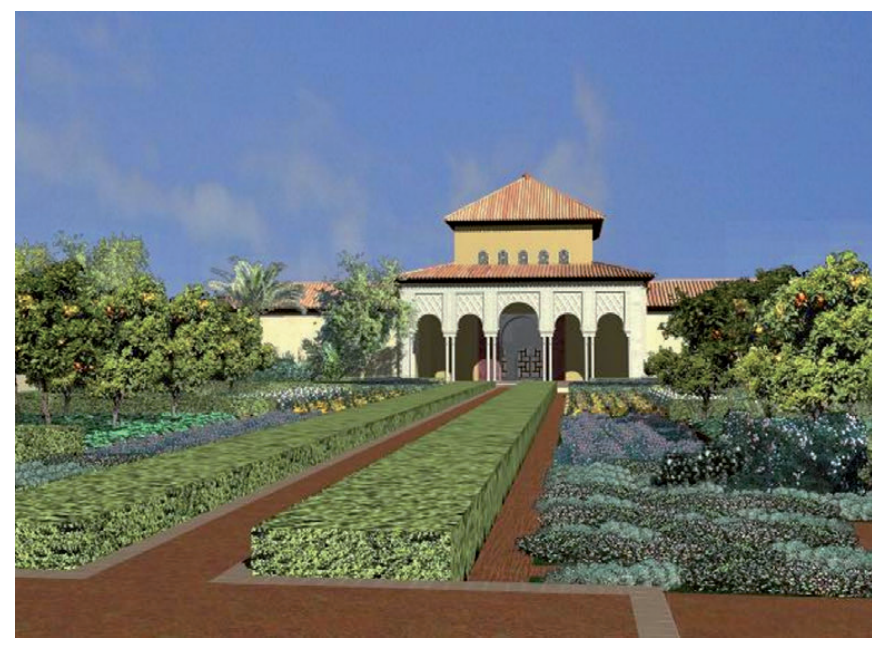

Figura 22. La qubba del Cuarto Real de Santo Domingo con la reconstrucción virtual de su pórtico 
qubba-s usadas sin duda como espacios de recepción y protocolo. La qubba occidental, que hemos analizado con más detenimiento, fue seguramente un salón del trono. Sus precedentes andalusíes así lo confirmarían. El ejemplo más inmediato lo constituye el salón de Comares de la Alhambra, salón del trono de los sultanes nazaríes y verdadero espacio lleno de simbolismos ${ }^{49}$, que muy posiblemente estaría presente en la mente de al-Mansur a través de crónicas y relatos de los emigrados andalusíes ${ }^{50}$.

En la Alhambra, aparte de la gran qubba de Comares, existen otras muchas, generalmente con función de miradores o pabellones de jardín: palacio del Partal, torre de Machuca o de los Puñales, mirador del palacio del exconvento de San Francisco, torre de los Abencerrajes y miradores del

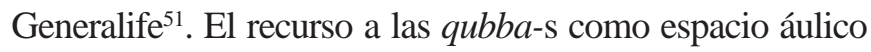
ligado a la simbología del poder lo mismo que al disfrute de los espacios en que estas se asentaban no se limita sólo a la Alhambra ni tan siquiera a los territorios musulmanes de la Península. Tal función tuvo la qubba del Cuarto Real de Santo Domingo, primer ejemplo nazarí, de la segunda mitad del siglo XIII ${ }^{52}$. Resulta significativa la enorme semejanza que debía presentar este edificio granadino con el pabellón del palacio de Marrakech, pese a que éste lo doblaba prácticamente en tamaño (Fig. 7 y 22).

Pero el uso de la qubba como salón del trono tiene precedentes también en la arquitectura del reino de Castilla, no sólo en construcciones coetáneas a las de la Alhambra, como pueden ser los palacios de Pedro I en el Alcázar de Sevilla y quizás en el de Tordesillas, sino de fecha anterior como es el caso del Alcázar Real de Guadalajara, no obstante todos ellos de clara ascendencia andalusí.

El uso de columnas pareadas del que después hablaremos, no es habitual en la arquitectura andalusí pero tenemos dos ejemplos claros en el período nazarí. Uno es el que testimonia la documentación gráfica antigua sobre el Cuarto Real de Santo Domingo, cuyo pórtico parece estuvo sostenido por columnas dobles (Fig. 22). El otro vuelve a ser el del Patio de los Leones de la Alhambra en donde hay agrupaciones de dos y de tres columnas, aunque en este caso los capiteles sean siempre independientes y no labrados en el mismo bloque como en al-Badi'.

Todos los paralelos antes referidos muestran claramente que en el palacio levantado por Ahmad al-Mansur

\footnotetext{
49 Cabanelas 1988: 81-90.

50 Esta qubba de al-Badi' supera ampliamente con sus $13 \mathrm{~m}$ de lado las dimensiones de la de Comares que sólo alcanza los $11.30 \mathrm{~m}$, pese a ser la mayor de que tenemos noticia en al-Andalus.

51 Orihuela 1996: 62, 76, 52, 210-212.

52 Orihuela 1996: 315-333.
}

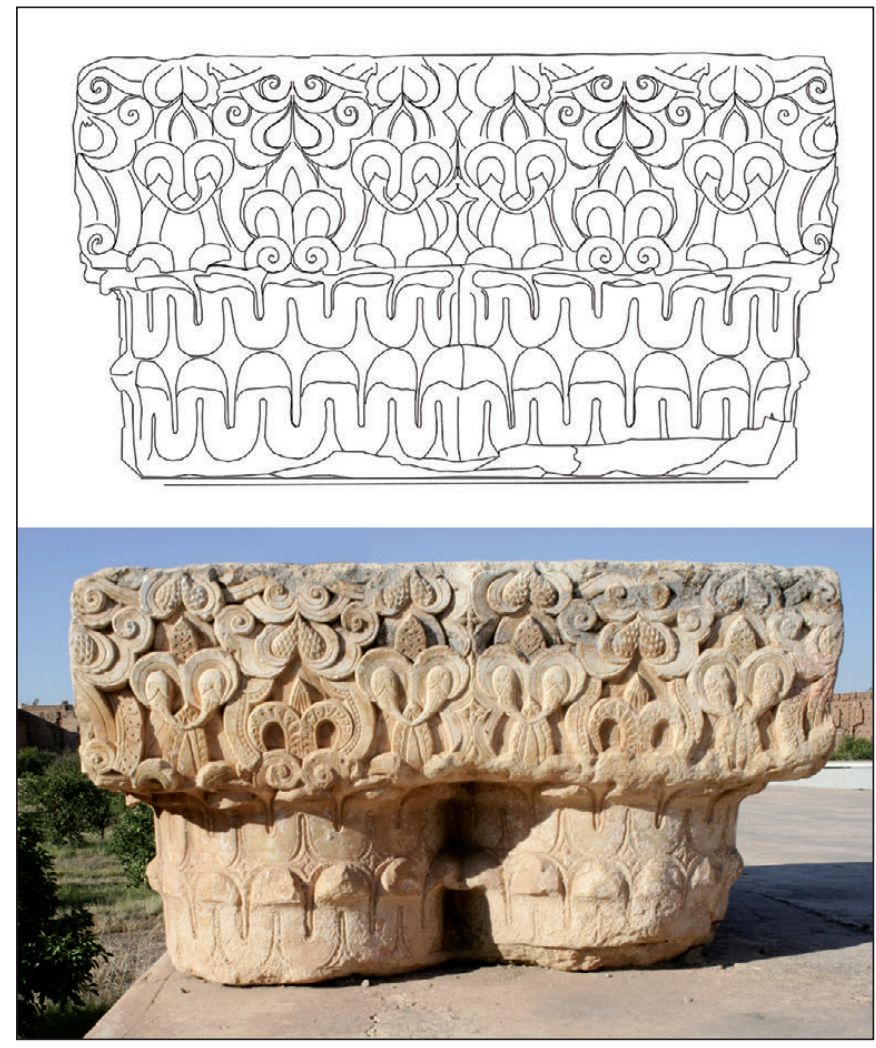

Figura 23. Capitel de columnas pareadas que se conserva en el palacio al-Badi'

en la qasba de Marrakech pervive la tradición de la arquitectura áulica andalusí, a la que evidentemente recurrió el sultán sa'adí como soporte de su legitimidad y de sus ambiciones políticas entre las que sin duda se encontraba la asunción del título califal, que si bien finalmente no llegó a utilizar, sí parece que aspiró a detentar y trató de justificar mediante actos que, como la construcción de un gran palacio, le asemejaban a los grandes califas a quienes quiso emular ${ }^{53}$.

\section{HI PÓTESIS DE RECONSTRUCCIÓN DEL PABELLÓN}

Toda la información recogida ha permitido definir con bastante fiabilidad tanto la planta como los alzados del pabellón en sus líneas generales (Fig. 10). Pero quedan algunos detalles aún por precisar, incluso de tipo métrico. El principal se refiere a la altura de las columnas del pórtico que rodeaba el pabellón ${ }^{54}$, para las que el único

\footnotetext{
53 García-Arenal 2009: 122-23.

${ }^{54}$ La casi totalidad de las columnas fue trasladada a Mekinez por Mulay Ismail para su reempleo en la construcción de sus palacios (Barrucand 1976: 155). Un número importante de ellas quedó, al parecer, en la localidad de Safi, puerto más cercano a Marrakech en la costa atlántica, sin duda en un viaje inacabado hacia la nueva capital alauí. Agradezco al Prof. Hamid Triki esta información.
} 

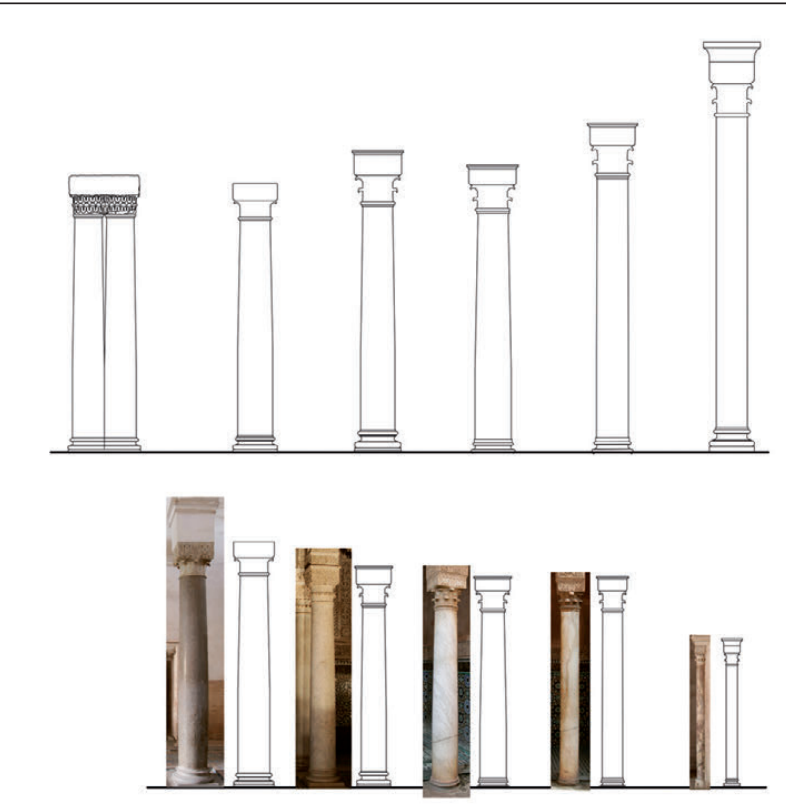

Figura 24. Análisis de medidas y proporciones de distintas columnas del mausoleo de los sa'adíes en Marrakech. En la fila inferior se dibujan las distintas columnas en su verdadera magnitud y en la superior cada una de ellas redimensionadas con el diámetro de los capiteles de al-Badi' conservados. A la izquierda la dimensión adoptada para la reconstrucción

dato que poseemos es la existencia de dos grupos de capiteles conservados en el propio monumento. Se trata de un capitel doble y otro triple de disposición angular que indican la existencia de columnas pareadas y triples en ángulo ${ }^{55}$. Hemos procedido a dibujarlos también mediante su restitución estereoscópica (Fig. 23).

Para plantear una hipótesis sobre las dimensiones de las columnas hemos recurrido a analizar las del edificio coetáneo más directamente relacionado con este palacio, que es el panteón de los sa'adíes situado a escasa distancia de al-Badi’ y construido en su parte más importante por el mismo Ahmad al-Mansur ${ }^{56}$. El proceso seguido ha sido dibujar las columnas allí existentes en su verdadera magnitud y escalarlas después de acuerdo con el diámetro de los capiteles conservados en al-Badi', obteniendo así una serie de columnas con distintas proporciones (Fig. 24). Las correspondientes a la sala llamada de las Doce Columnas y que contiene la tumba de al-Mansur, son las que proporcionan una solución más acorde con las medidas de los otros elementos, especialmente la altura del techo del pórtico determinada por los empotramientos de sus vigas (Figs. 4 y 25).

\footnotetext{
55 Estos capiteles están labrados en una caliza muy fina que parece proceder de las canteras de Imi n’Tala (Allain 1956: 111-112)

56 Deverdun 1959: 405
}

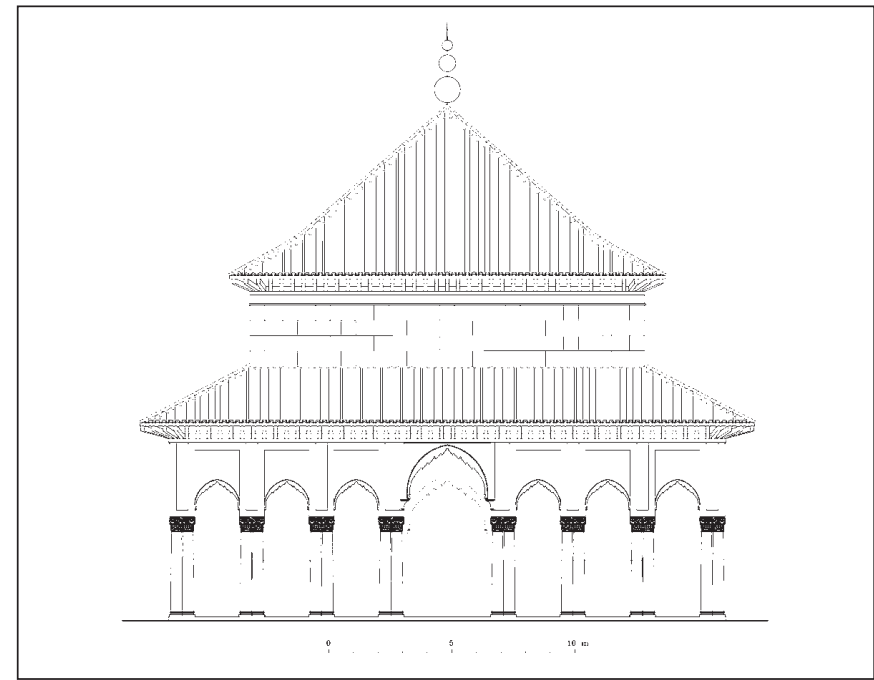

Figura 25. Alzado del pabellón occidental según la reconstrucción propuesta

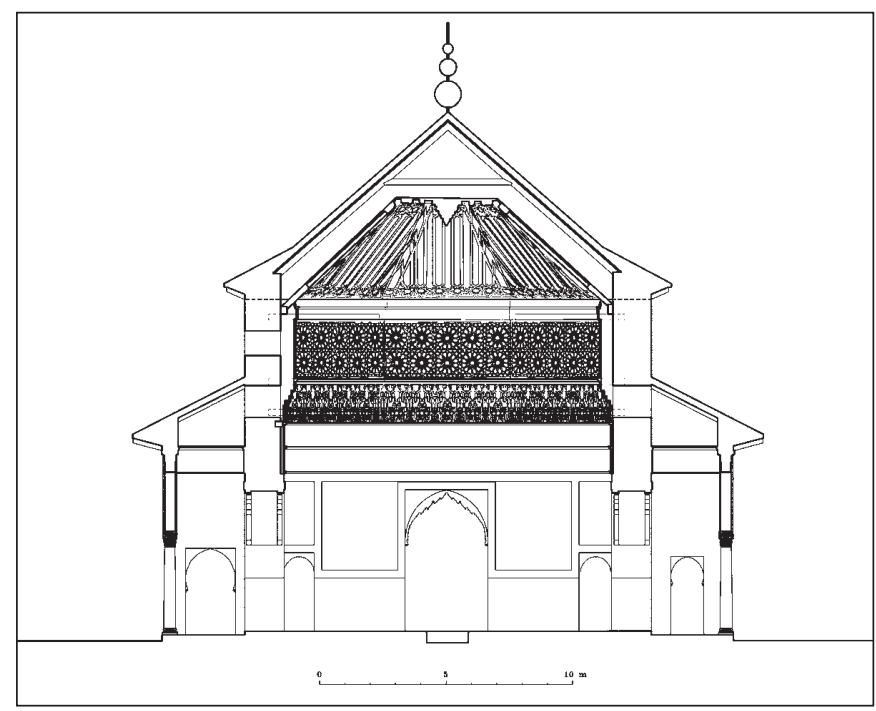

Figura 26. Sección hipotética por el eje norte-sur del pabellón occidental

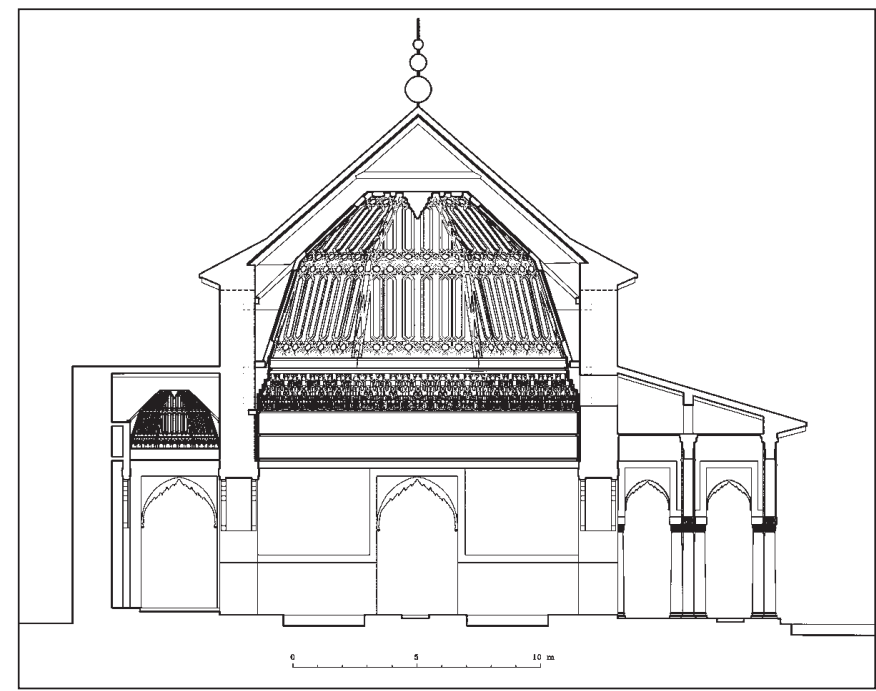

Figura 27. Sección hipotética por el eje este-oeste del pabellón occidental mostrando otra de las posibles soluciones del techo 


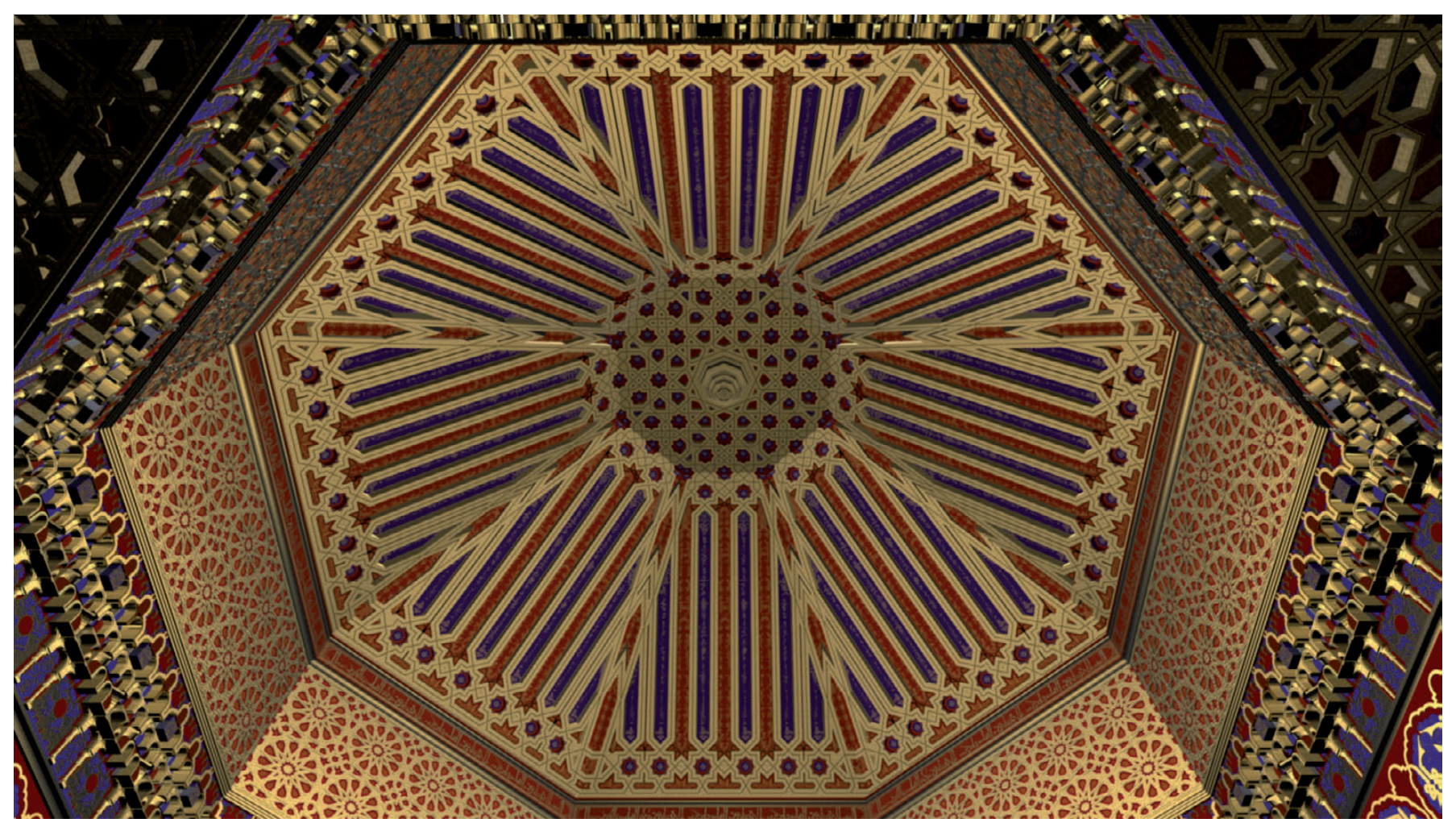

Figura 28. I magen virtual del techo de la qubba. (Imagen realizada por M. González y L. Berenguel sobre hipótesis de A. Almagro)

Para definir los detalles de la decoración se ha recurrido también a la ornamentación de esa misma sala en la que encontramos los mismos materiales y formas que cabe suponer hubo en el palacio. Zócalos de alicatado, de los que existen algunos restos en la sala norte del conjunto, paramentos recubiertos de yesería, aliceres de madera y arcos de perfil de lambrequines con la composición de arco central de mayor tamaño y arcos menores rematados por paños de sebka.

Las huellas que los elementos de madera han dejado en los muros resultan muy elocuentes permitiendo establecer unas hipótesis generales, y sobre todo, conocer dónde terminaban los paños de yesería y dónde comenzaba la decoración en madera. Desgraciadamente para la forma del techo, aparte de saber que tuvo disposición ochavada, no podemos precisar mucho más ya que no hay otros indicios que nos permitan presentar una hipótesis plenamente fiable entre las varias posibles. De entre éstas podemos plantear dos como más plausibles. Una se basaría en una simple armadura de tres paños, con ocho faldones y almizate, que arrancaría sobre un tambor octogonal (Fig. 26), a semejanza del techo de la capilla de San Miguel de la Seo del Salvador de Zaragoza, conocida como la Parroquieta ${ }^{57}$. Otra hipótesis podría

57 Borrás 1985: vol. I, lám. 27-28. contener una armadura de cinco paños, también ochavada (Fig. 27), como el techo del presbiterio de la iglesia del monasterio de Santa Clara de Tordesillas ${ }^{58}$. En ambos casos cabría que la propia armadura soportara la cubierta o más probablemente, que hubiera otra armadura cuadrada más simple, de par y nudillo, para conformar el tejado.

En nuestra hipótesis que hemos representado en imágenes de síntesis, hemos optado por la primera solución, por ser más sencilla de definir (Fig. 28). No obstante, la existencia de una armadura de cinco paños, aunque de planta cuadrada, en la llamada sala de las doce columnas del mausoleo de los sa' adíes ${ }^{59}$, al que hemos hecho ya referencia, obliga a considerar igualmente como muy posible la otra hipótesis. Evidentemente, dentro de ambas soluciones cabe también pensar en casi infinitas variantes en lo que respecta al tipo de lazo utilizado o a otras muchas opciones ornamentales.

Con todos estos datos se ha planteado y dibujado la hipótesis que ha servido para realizar la reconstrucción virtual del conjunto. En ella se hace especial hincapié en incorporar la policromía como un componente esencial en la conformación de la imagen del edificio (Fig. 29). La presencia del

\footnotetext{
58 López Guzmán 2000: 313.

59 Marçais 1954: 393, 399. Deverdun 1959: 408.
} 


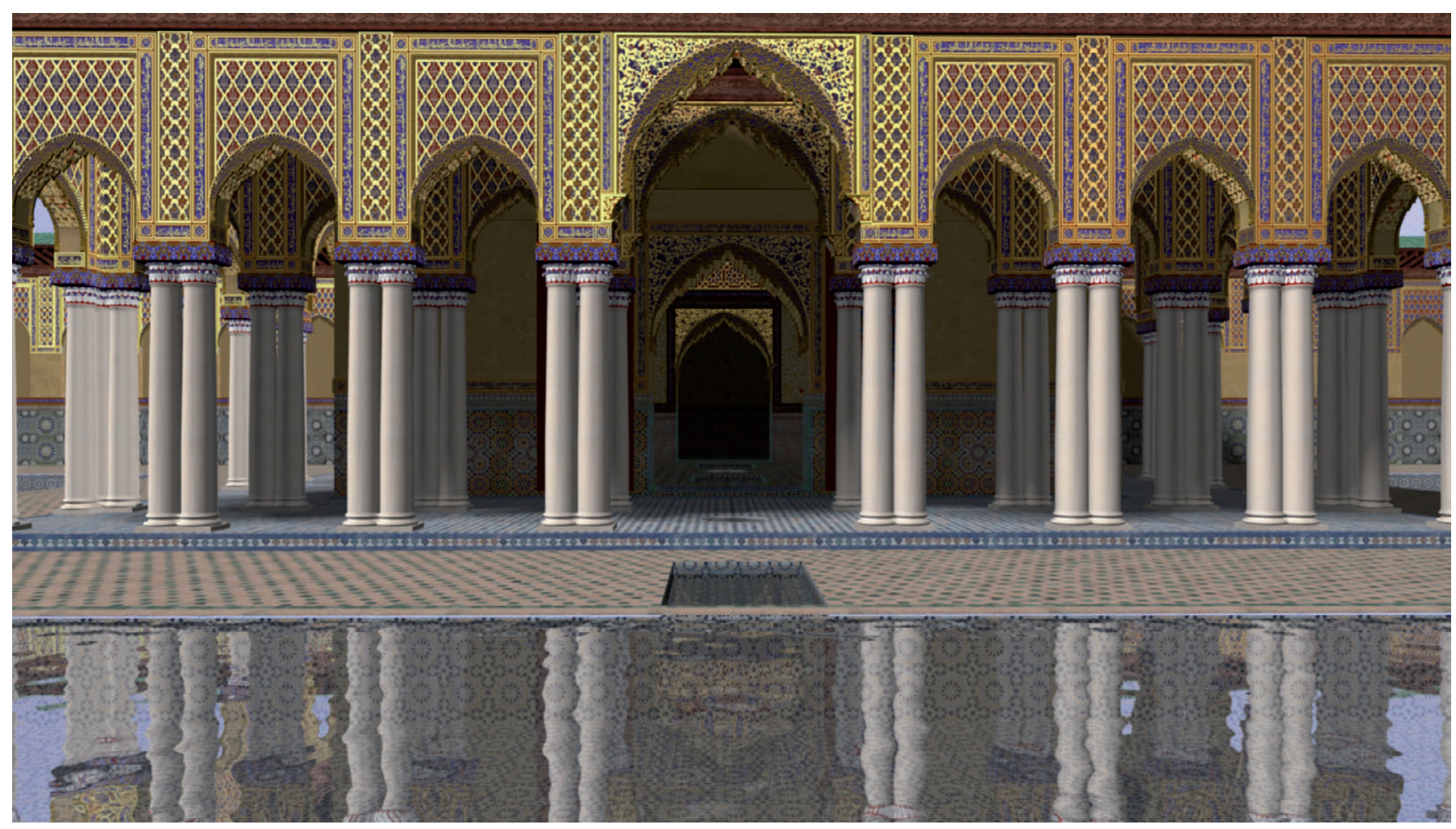

Figura 29. Imagen virtual del pórtico con su policromía y su reflejo en la alberca. (Imagen realizada por M. González y L. Berenguel sobre hipótesis de A. Almagro)

agua y su comportamiento como elemento especular en el que se refleja la arquitectura, contribuye igualmente a reproducir los efectos perceptivos que conferían a este singular monumento unas características que lo emparentan directamente con sus precedentes andalusíes (Fig. 30). También la vegetación como elemento primordial en la creación del ambiente del patio, que por las desmesuradas proporciones adquiere aquí un protagonismo especial, se percibe en la reconstrucción virtual de un modo más próximo a lo que pudo ser la realidad respecto a la pobre vegetación que hoy ocupa los parterres (Fig. 6-7).

Sin embargo, las imágenes de síntesis creadas nunca deberían tomarse como una representación verídica de lo que fue la realidad original del monumento, sino más bien como una evocación de sus características formales y perceptivas. El necesario recurso a tomar de otros edificios coetáneos elementos de detalle que nos permitan recrear un ambiente suficientemente real como para percibir el mayor número posible de las cualidades que esta arquitectura poseía (Figs. 31), nos obliga a reconocer que sin duda las soluciones originales fueron otras, dada la enorme creatividad de los artesanos que intervenían en estas construcciones, que raramente repetían formas ornamentales de manera mimética. Por este motivo, la observación de estas imágenes debe hacerse sin fijar nuestra atención en los detalles, sino sólo en la percepción general del espacio, que es el verdadero objetivo que se pretende. Debe ser principalmente el recuerdo que quede en nuestra memoria después de una visión fugaz de estas recreaciones lo que debemos retener. La mayor parte de las soluciones adoptadas son puras conjeturas que pueden ser revisadas y enmendadas con otras propuestas, seguramente sin muchas posibilidades de aseverar ninguna. En todo caso, siendo aproximaciones posibles, facilitan el objetivo ya apuntado de suscitar en nuestra mente impresiones cercanas a las que pudieron experimentar visitantes y usuarios de este singular palacio.

\section{AGRADECI MI ENTOS}

Este trabajo se inició en el marco de un proyecto de cooperación inter-universitaria, entre la Escuela de Estudios Árabes y la Universidad Caid Ayyad de Marrakech financiado por la AECID en 2005, gracias al cual pudimos realizar la toma de datos. Los trabajos de gabinete se han desarrollado dentro de sendos proyectos del Plan Nacional (HAR2011-29963 ART) e Intramural del CSIC. Diversas circunstancias fueron retrasando su 


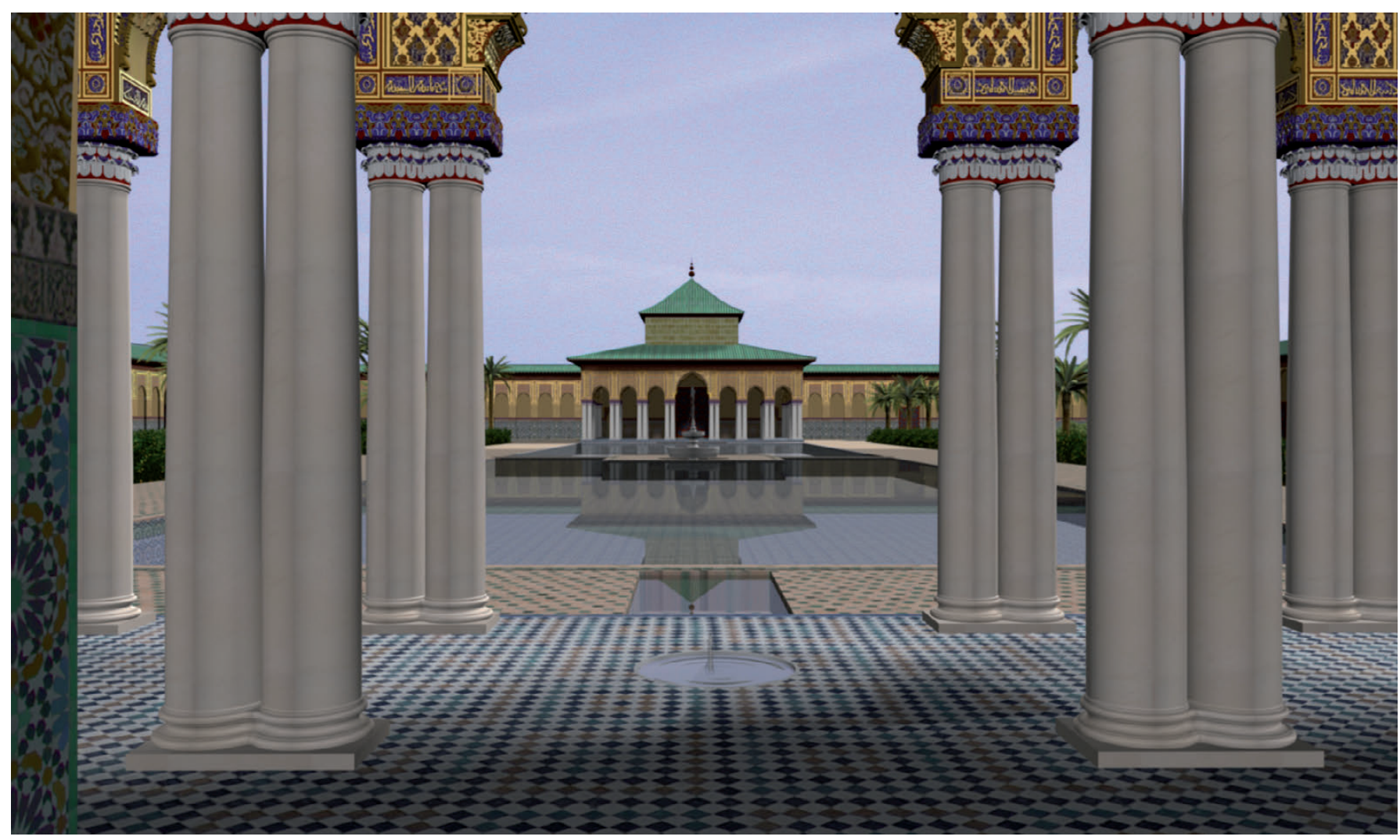

Figura 30. El pabellón oriental visto desde el pórtico del occidental, en una imagen virtual. (Imagen realizada por M. González y L. Berenguel sobre hipótesis de A. Almagro)

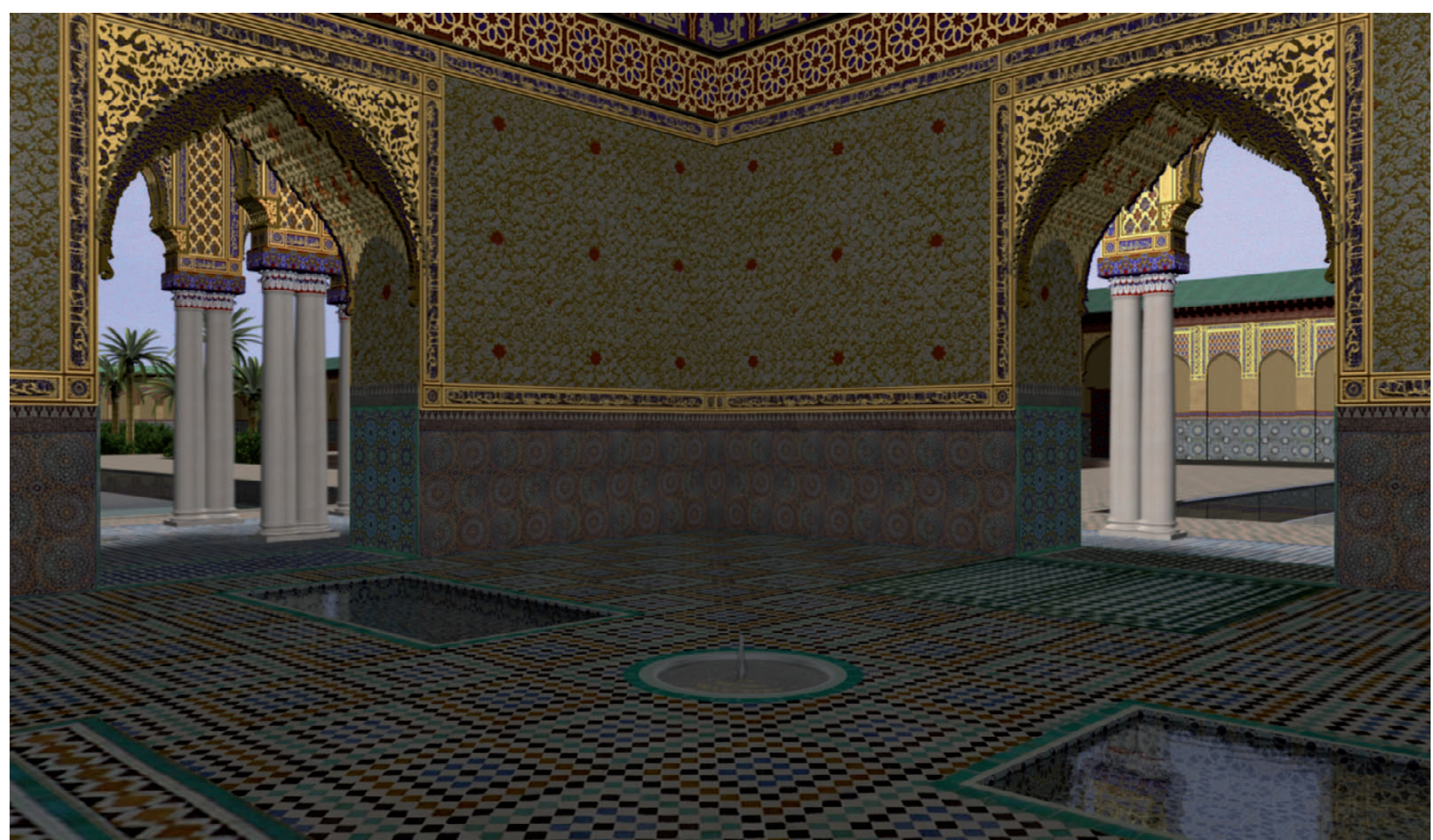

Figura 31. Imagen virtual del interior del pabellón occidental. (Imagen realizada por M. González y L. Berenguel sobre hipótesis de A. Almagro) 
desarrollo que se ha circunscrito hasta ahora al estudio del pabellón occidental. Deseo expresar mi agradecimiento al Prof. Muhammad El-Faïz de la Universidad Caid Ayyad, al Sr. Faissal Cherradi, a la sazón inspector de monumentos de Marrakech, así como al Prof. Hamid Triki por la colaboración prestada para el desarrollo de este trabajo.

\section{ANEXO}

Se acompaña un vídeo en la versión html on-line.

\section{BI BLI OGRAFÍ A}

Allain, C. 1956: “La carrière saadienne et les chapitaux d’Imi n’Tala”, Hesperis, XLIII, p. 101-115.

Almagro, A., 1999: "El Patio del Crucero de los Reales Alcázares de Sevilla”, Al-Qantara, XX, p. 331-376.

Almagro, A., 2002: "El análisis arqueológico como base de dos propuestas: El Cuarto Real de Santo Domingo (Granada) y el Patio del Crucero (Alcázar de Sevilla)”, Arqueología de la Arquitectura, 1, p. 175-192.

Almagro, A., 2007a: “An Approach to the Visual Analysis of the Gardens of Al-Andalus”, Conan, M. (ed.), Midle East Garden Tradition: Unity and Diversity, p. 55-73. Dumbarton Oaks, Trustees for Harvard University, Washington.

Almagro, A., 2007b: “Una nueva interpretación del patio de la Casa de Contratación del Alcázar de Sevilla”, Al-Qantara, XXVIII, 1, p. 181-228. doi: 10.389/alqantara.2007.v28.i1.35.

Almagro, A., 2008: Palacios Medievales Hispanos. Discurso del Académico Electo Excmo. Sr. D. Antonio Almagro Gorbea... Real Academia de Bellas Artes de San Fernando, Madrid.

Almagro, A., Navarro, J. y Orihuela, A., 2008: "Metodología en la conservación del patrimonio arquitectónico medieval”, Saiz-Jiménez, C. y Rogerio-Candela, M. A. (eds.), La Investigación sobre Patrimonio Cultural, Sevilla, p. 87-98.

Almagro, A., 2011: "Photogrammétrie pour la recherche architecturale: vingt ans d'experience à l'École d'Études Arabes”, Revue Française de Photogrammétrie et Télédétection, 196, p. 10-20.

Almagro, A., 2012: Al-Badi. Marrakech (DVD). Granada.

Almagro Vidal, A., 2008: El concepto de espacio en la arquitectura palatina andalusí. Un análisis perceptivo a través de la infografía, Madrid.

Barrucand, M., 1976: L'Architecture de la Qasba de Mulay Ismaïl à Meknès, Études et Travaux d’Archeologie Marocaine, VI, Rabat.

Barrucand, M., 1985: Urbanisme princier en Islam. Meknès et les villes royales islamiques post-médiévales. Paris.
Borrás Gualis, G., 1985: Arte Mudéjar Aragonés, 2 vols. Zaragoza.

Bressolette, H. y Delarozière, J., 1978-1979: "El Mosara, jardin royal des Mérinides”, Hespéris-Tamuda, XVIII, pp. 51-61.

Cabanelas Rodríguez, D., 1988: El techo del Salón de Comares de la Alhambra. Decoración, Policromía, Simbolismo y Etimología. Granada.

Cabanelas, D. y Fernández Puertas, A., 1981: "El poema de la fuente de los Leones”, Cuadernos de la Alhambra, 15-17, p. 3-88.

Cristini, V. y Ruiz Checa, J.R., 2012: “Core, connectors and crust: Methodological restoration options for reinforced rammed earth wall with bricks”, en Mileto, C., Vegas, F. y Cristini, V. (eds.), Rammed Earth Conservation, p. 297-302. Leiden.

Deverdun, G., 1959: Marrakech, des origines à 1912, 2 vols. Rabat.

El Faïz, M., 2000: “L’Agdal e i giardini di Marrakech nella storia della città”, L’Agdal di Marrakech. Fondazione Benetton Studi Ricerche, Treviso.

Estelle, J.B., 1931: “Mémoire adressé à Monseigneur de Maurepas, 2 avril 1698”, Les Sources Inédites de l'Histoire du Maroc, Deuxième série, Dynastie Filaelienne, France, t. IV, en Cenival, P. de.: Les Sources Inédites de l'Histoire du Maroc, Deuxième série, Dynastie Filaelienne, France. p. 384-408, Paris.

Fernández Puertas, A., 2006: “La Alhambra. El Alcázar del Sultán (hoy Comares) y el Alcázar del Jardín Feliz (hoy Leones), según los Diwanes de Ibn al-Jatib e Ibn Zamrak”, en Páez López, J. (dir.) Exposición: Ibn Jaldún. El Mediteráneo en el siglo XIV: Auge y declive de los Imperios. La península Ibérica. El entorno mediterráneo, p. 100-127. Granada.

García-Arenal, M., 2009: Ahmad al-Mansur: The Biginings of Modern Morocco. Oxford.

García Pulido, L. J., 2013: El territorio de la Alhambra. Evolución de un paisaje cultural remarcable. Patronato de la Alhambra y GeneraliceUniversidad de Granada, Granada.

al-Ifrani, Muhammad Sagir, 1888-1889: Nozhet-Elhâdi, histoire de la dynastie saadienne au Maroc (1511-1670). Houdas, O. (trad.). Ernest Leroux, Paris (2 vols.).

Koehler, H., 1940: “La Kasba saadienne de Marrakech, d'après un plan manuscrit de 1585”, Hesperis, XXVII, p. 1-20.

López Guzmán, R., 2000: Arquitectura Mudéjar. Madrid.

Marçais, G., 1954: L'architecture musulmane d'Occident. Tunisie, Algérie, Maroc, Espagne, Sicile. Paris.

Meunier, J., 1957: "Le Grand Riad et les bâtiments saadiens du Badi selon le plan publié par Windus”, Hespéris, XLIV, p. 129-134.

Murphy, J.C., 1813: The Arabian antiquities of Spain. London.

Navarro Palazón, J. Jiménez Castillo, P. 1995: El Castillejo de Monteagudo: Qasr ibn-Sa'd, en Navarro Palazón, J. (ed.) Casas y palacios de al-Andalus. Siglos XII-XIII, p. 63-103, Barcelona.

Nuere, E., 1989: La carpintería de armar española. Madrid.

Orihuela Uzal, A., 1996: Casas y palacios nazaríes. Siglos XIII-XV. Barcelona.

Torres Balbás, L. 1958: "Patios de crucero”, Al-Andalus, XXIII, p. 171-192.

Windus, J., 1725: A journey to Makinez; The Residenz of the Present Emperor of Fez and Marocco on the Occasion of Commodore Stewart's Embassy thither for the Redemtion of the British Captives in the year 1721. London. 